\title{
Current EU regulatory requirements for the assessment of chemicals and cosmetic products: challenges and opportunities for introducing new approach methodologies
}

\author{
Francesca Pistollato ${ }^{1}$ - Federica Madia ${ }^{1} \cdot$ Raffaella Corvi $^{1}$. Sharon Munn ${ }^{1}$ - Elise Grignard ${ }^{1}$ - Alicia Paini ${ }^{1}$. \\ Andrew Worth $^{1}$ - Anna Bal-Price ${ }^{1}$ - Pilar Prieto ${ }^{1}$ - Silvia Casati ${ }^{1}$. Elisabet Berggren ${ }^{1}$. Stephanie K Bopp ${ }^{1}$. \\ Valérie Zuang ${ }^{1}$ (i)
}

Received: 19 November 2020 / Accepted: 18 March 2021 / Published online: 13 April 2021

(c) The Author(s) 2021

\begin{abstract}
The EU Directive 2010/63/EU on the protection of animals used for scientific purposes and other EU regulations, such as REACH and the Cosmetic Products Regulation advocate for a change in the way toxicity testing is conducted. Whilst the Cosmetic Products Regulation bans animal testing altogether, REACH aims for a progressive shift from in vivo testing towards quantitative in vitro and computational approaches. Several endpoints can already be addressed using non-animal approaches including skin corrosion and irritation, serious eye damage and irritation, skin sensitisation, and mutagenicity and genotoxicity. However, for systemic effects such as acute toxicity, repeated dose toxicity and reproductive and developmental toxicity, evaluation of chemicals under REACH still heavily relies on animal tests. Here we summarise current EU regulatory requirements for the human health assessment of chemicals under REACH and the Cosmetic Products Regulation, considering the more critical endpoints and identifying the main challenges in introducing alternative methods into regulatory testing practice. This supports a recent initiative taken by the International Cooperation on Alternative Test Methods (ICATM) to summarise current regulatory requirements specific for the assessment of chemicals and cosmetic products for several human health-related endpoints, with the aim of comparing different jurisdictions and coordinating the promotion and ultimately the implementation of non-animal approaches worldwide. Recent initiatives undertaken at European level to promote the 3 Rs and the use of alternative methods in current regulatory practice are also discussed.
\end{abstract}

Keywords EU regulatory requirements · Industrial chemicals $\cdot$ Cosmetic products · Cosmetic ingredients $\cdot$ Human health · Alternatives to animal testing $\cdot 3 \mathrm{Rs} \cdot \mathrm{REACH} \cdot \mathrm{Cosmetic}$ products regulation

\section{Introduction}

The EU Directive 2010/63/EU (2010) on the protection of animals used for scientific purposes, other pieces of EU legislation, such as Regulation (EC) No 1907/2006 concerning the Registration, Evaluation, Authorisation and Restriction of Chemicals [REACH (2020g)] and the Regulation (EC) No 1223/2009 on cosmetic products (2020e), advocate for a change in the way toxicity testing is conducted, proposing

Valérie Zuang

valerie.zuang@ec.europa.eu

1 Directorate F-Health, Consumers and Reference Materials, Unit F3 Chemicals Safety and Alternative Methods,

European Commission, Joint Research Centre (JRC), Via E.

Fermi, 2749. TP126, 21027 Ispra, VA, Italy a shift from in vivo testing, towards non-animal approaches based on in vitro and computational methods. This is considered essential to gather a deeper mechanistic understanding of chemical effects, taking into account human biology, and limiting (or avoiding) concerns associated with responses in test animals and humans due to interspecies differences.

At the European level, the need to integrate up-to-date in vitro and in silico methods and models in existing or new regulatory testing strategies has been promoted in Directive 2010/63/EU (2010), which includes a number of duties aimed at fostering the Replacement, Reduction and Refinement (i.e., Three Rs ${ }^{1}$ ) of animal testing. Additionally, REACH (2020g) and the Cosmetic Products Regulation (2020e) have either contributed to the implementation of the 3Rs by, respectively referring to and encouraging the use

1 Three Rs and 3Rs are used interchangeably. 
of alternatives to animal testing, or banning animal testing altogether. Along this line, for some specific toxicological endpoints (e.g., skin corrosion and irritation, serious eye damage and irritation, skin sensitisation, and mutagenicity and genotoxicity), the potential hazard of chemicals is often evaluated using non-animal approaches. Nevertheless, for other endpoints, such as acute systemic toxicity, repeated dose toxicity and reproductive and developmental toxicity, the regulatory requirements, and thus chemical safety evaluation, still heavily relies on the use of animals.

Understanding current regulatory requirements specific for the assessment of chemical and cosmetic ingredient effects on human health is essential to identify possible knowledge gaps, and evaluate how alternative (non-animal) methods could be integrated in current regulatory practice. This is in line with recent initiatives taken by the International Cooperation on Alternative Test Methods (ICATM) (https://ec.europa.eu/jrc/en/eurl/ecvam/alter native-methods-toxicity-testing/advisory-bodies/icatm), whose members include EURL ECVAM (European Union Reference Laboratory for Alternatives to Animal Testing) of the European Commission's Joint Research Centre (JRC), ICCVAM (the US Interagency Coordinating Committee on the Validation of Alternative Methods) at the National Institute of Environmental Health Sciences, JaCVAM (Japanese Center for the Validation of Alternative Methods) at the National Institute of Health Sciences, Health Canada, and KoCVAM (South Korean Center for the Validation of Alternative Methods) at the National Institute of Environmental Health Sciences, with ad hoc participation from governmental institutions from Brazil, Singapore, China and Taiwan.

With the aim of comparing requirements in different jurisdictions and coordinating the promotion and ultimately the implementation of non-animal approaches worldwide, a summary of regulatory requirements for skin sensitisation testing across the countries represented by the ICATM partners was published (Daniel et al. 2018), together with a proposal of practical strategies to promote the adoption and regulatory use of defined approaches (DAs) ${ }^{2}$ for the assessment of skin sensitisation (Casati et al. 2018).

Here we summarise current EU regulatory requirements for the human health assessment of chemicals under REACH and the Cosmetic Products Regulation, considering the following toxicological endpoints: skin corrosion and irritation, serious eye damage/eye irritation, photo-induced toxicity, mutagenicity/genotoxicity, acute toxicity, skin sensitisation, repeated dose toxicity, carcinogenicity, reproductive and

\footnotetext{
${ }^{2}$ A DA consists of a fixed data interpretation procedure (DIP) applied to data generated with a defined set of information sources.
}

developmental toxicity, as well as absorption, distribution, metabolism and excretion (ADME) and toxicokinetics (TK), and identify the main challenges in current regulatory testing practice. We widen the discussion on the availability and advancement of new technologies and in vitro (non-animal) models, highlighting how new frameworks and initiatives undertaken at the European and international level could help to promote the 3Rs and implement twenty-first century test methods (NRC 2007) in current regulatory practice. Embracing a perspective that goes beyond specific regulatory silos and fostering knowledge sharing are essential to tackle complex human health-related endpoints.

\section{Current EU regulatory requirements of relevance for the safety assessment of chemicals and cosmetic products}

Several pieces of EU Regulations and Guidance Documents (GDs) relevant for the safety assessment of industrial chemicals and cosmetic products are in place (as summarized in Table 1), which describe the information needed to assess potential environmental and human health-related adverse effects of industrial chemicals and cosmetic products.

\section{Interface between REACH and the Cosmetic Products Regulation}

A joint ECHA-Commission statement (ECHA 2014a) clarified the interface between REACH and the Cosmetic Products Regulation. According to that statement, the animal testing ban in the Cosmetic Products Regulation concerns the tests needed to prove safety of the cosmetic products on the 'end users' (e.g., consumers). The marketing ban of cosmetic products that have been tested on animals is triggered, if the results of a study on vertebrate animals, required pursuant to the information requirements set out in the REACH Regulation, are relied on in the cosmetic product safety report under the Cosmetic Products Regulation to demonstrate the safety for the end user of products containing the registered substance exclusively used in cosmetic products. $^{3}$

However, the risks arising from other sources of exposure than the end use of cosmetic products are not assessed under the Cosmetic Products Regulation. In particular, REACH requires the evaluation of the risks to workers and the

\footnotetext{
3 "Testing carried out for cosmetics relevant endpoints on ingredients that have been specifically developed for cosmetic purposes and are exclusively used in cosmetic products would in the Commission's view always be assumed to be carried out 'in order to meet the requirements of this Directive/Regulation"' (Commission Communication COM/2013/135, Page 8).
} 


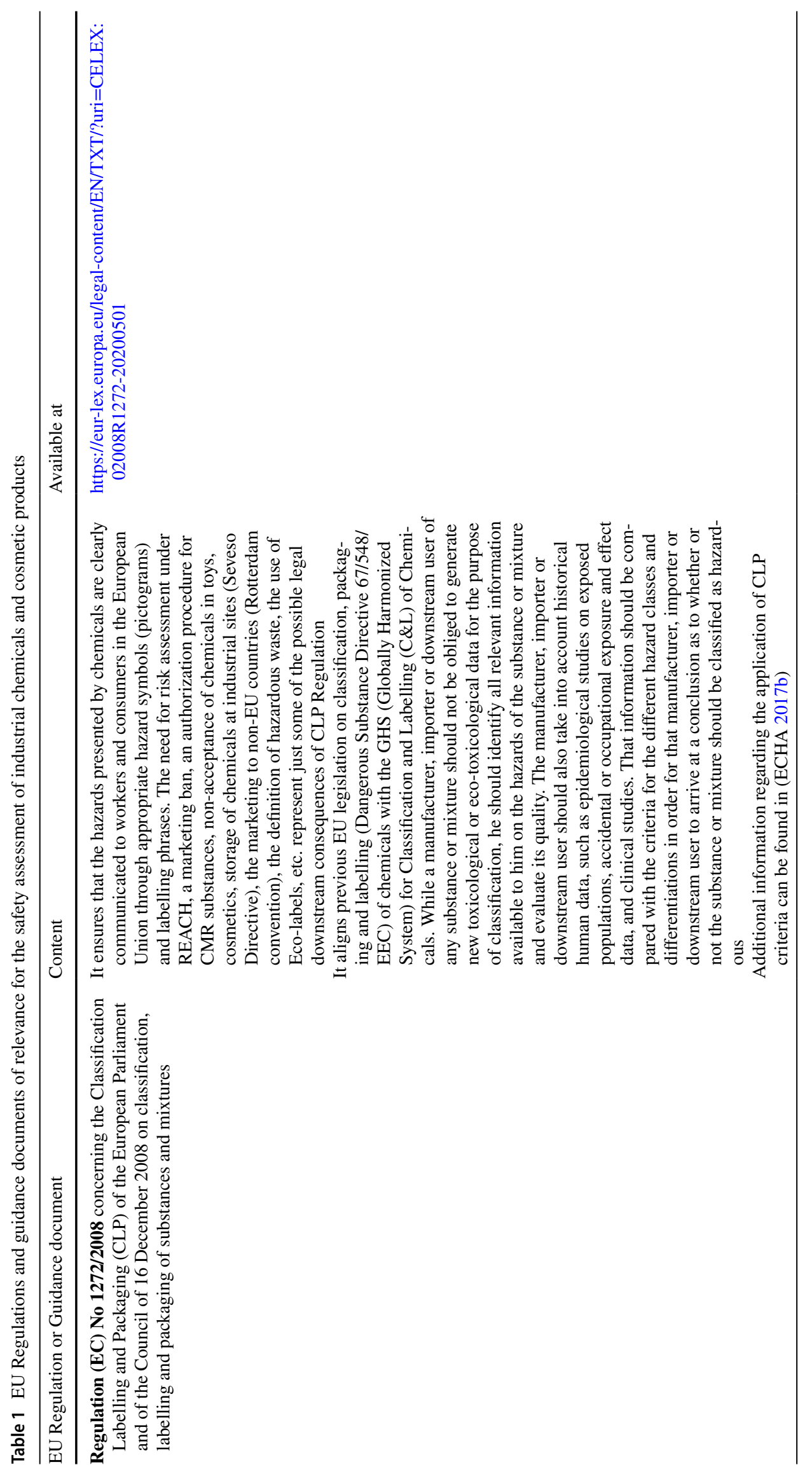




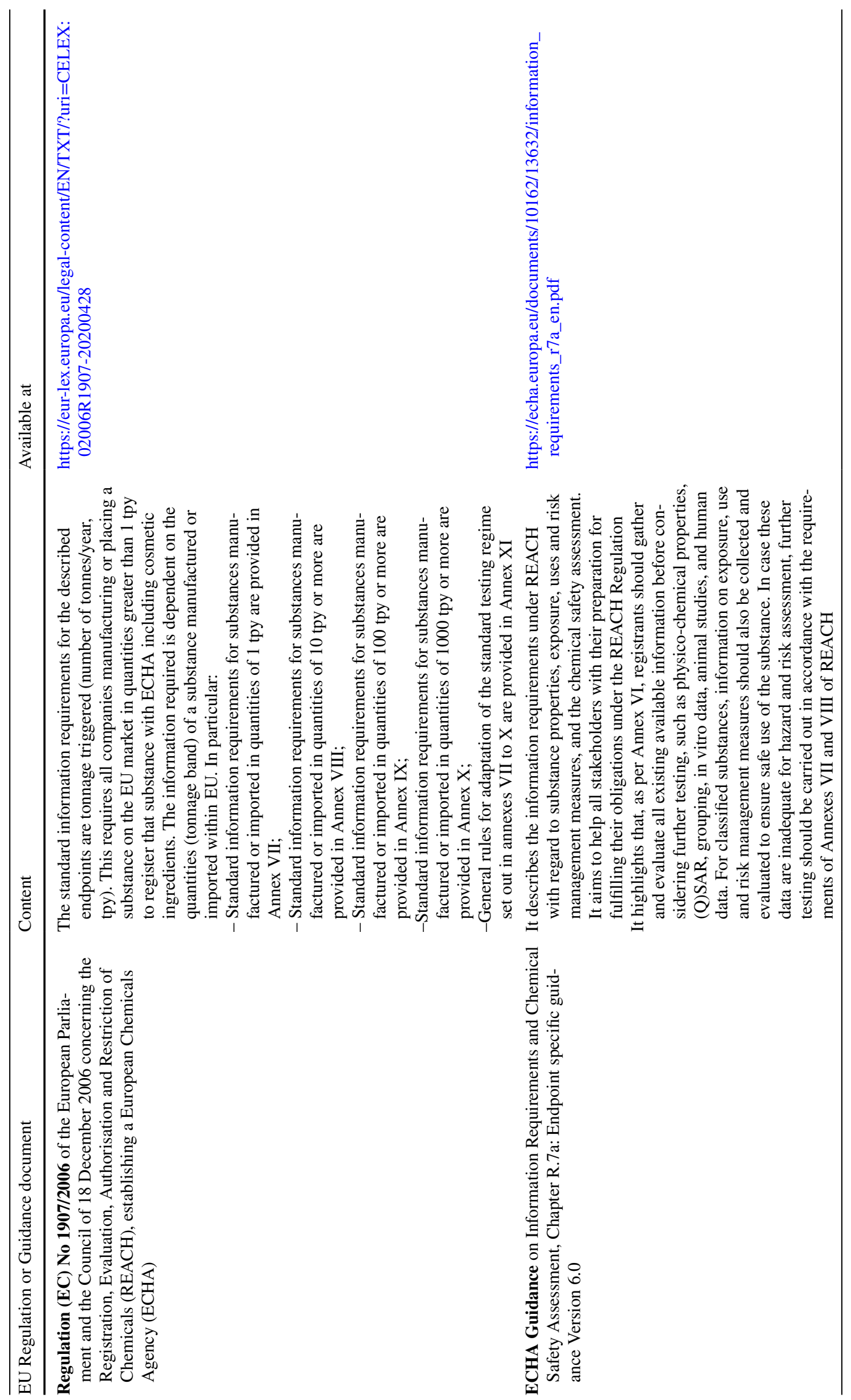




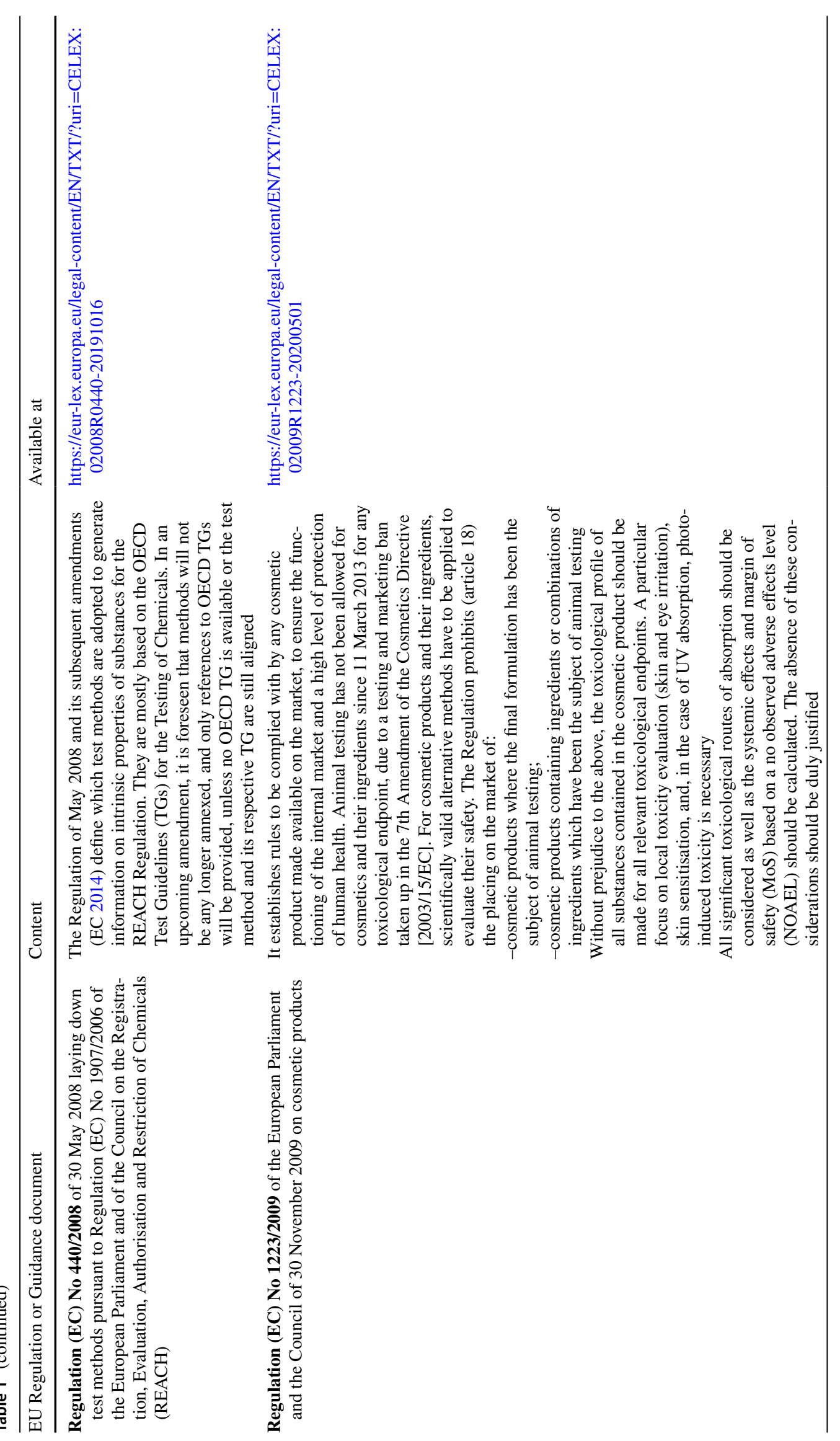




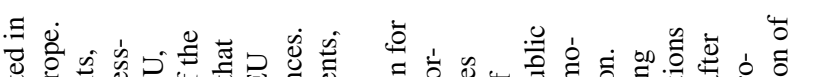

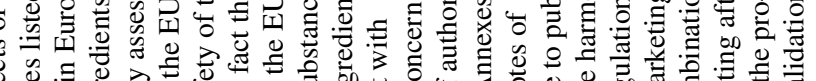

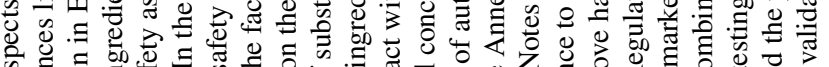
看.

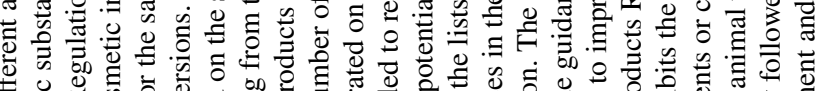

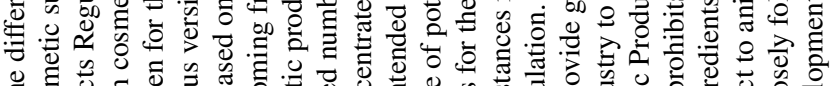

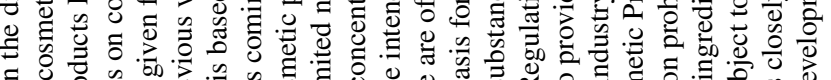

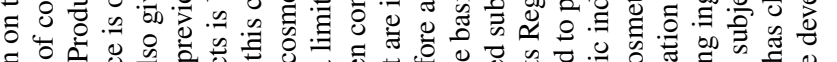

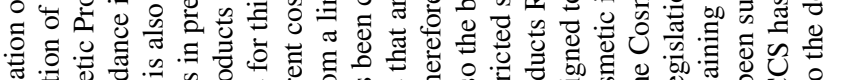

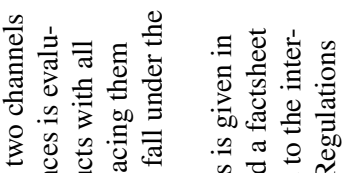

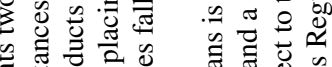

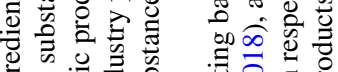

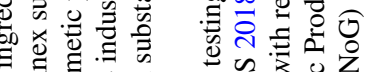

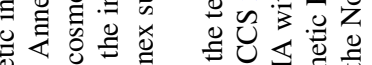

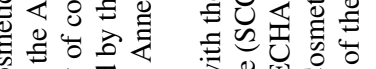

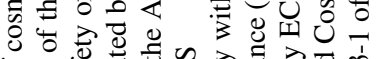

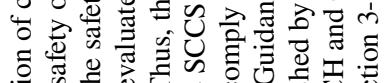

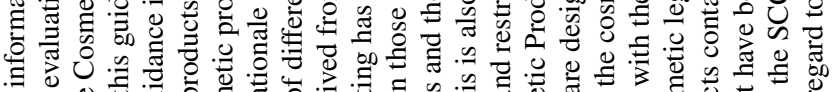

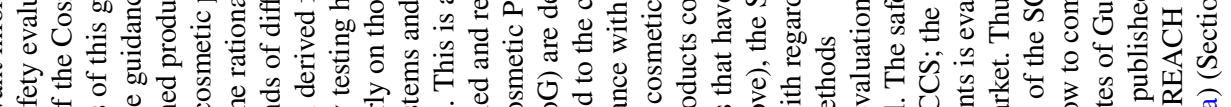

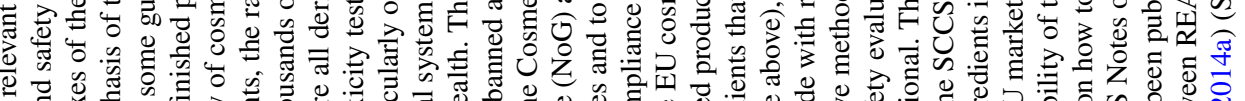

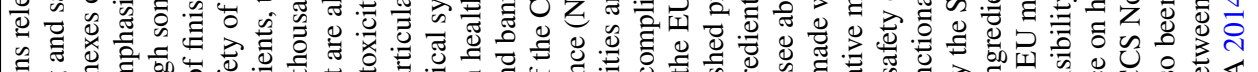

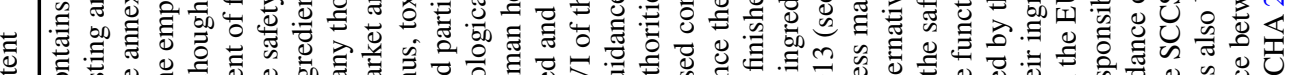


environment if the substance is covered by this Regulation. Regarding the relationship between REACH and the Cosmetic Products Regulation, decisions of the board of appeal of ECHA have been taken and are currently challenged by NGOs and Cosmetics industry, as reported in case numbers A-009-2018 ${ }^{4}$ and A-010-2018, ${ }^{5}$ which consider examples of substances exclusively used as an ingredient in cosmetic products.

Even if a substance is registered exclusively for cosmetic use, REACH animal testing requirements continue to apply, as a last resort, to assess the risk from exposure to workers and for all environmental endpoints. REACH does not contain an automatic exemption from the information requirements for registration if an ingredient is used as a substance in cosmetic products only. A registrant can benefit from an exemption only if he/she shows that the conditions for an adaptation (e.g., a waiver for the studies) are fulfilled. The animal testing ban under the Cosmetic Products Regulation, therefore does not prevent registrants from carrying out tests to comply with the information requirements of REACH. It is important to note though that tests on vertebrate animals should only be carried out as a very last resort, i.e., when no information which meets the information requirements is already available, and where no adaptation (e.g., where no alternative tests exist) can be applied. Moreover, it should also be noted that only the Court can provide a legally binding interpretation of Union law and more particularly on the relationship between the testing and marketing bans in the Cosmetic Products Regulation and the requirements of the REACH Regulation.

This manuscript focuses in particular on the regulatory requirements for relevant human-health related endpoints. More detailed information regarding these endpoints is reported in the next sections.

\section{Skin corrosion and irritation and serious eye damage/eye irritation}

Under CLP Regulation (2020f), the criteria for skin corrosive category and subcategories and skin irritation category are based on animal data; however, validated and accepted in vitro alternatives may also be used to help make classification decisions. The criteria for skin corrosion and irritation was updated to include criteria for the application of non-animal methods in the 8th revision of the GHS (UNGHS 2019), and the CLP Regulation implementing GHS within the EU, will be revised accordingly.

\footnotetext{
${ }^{4}$ https://echa.europa.eu/documents/10162/23010712/a-009-2018_ decision_en.pdf/237e31c9-2801-c160-7e5b-7ce81a3b7f17.

5 https://echa.europa.eu/documents/10162/23010712/a-010-2018_ decision_en.pdf/46612b84-29af-29ea-9192-b2506f33c8ce.
}

Category 1 applies to corrosive substances, which can be further divided into three subcategories: category 1A, 1B and $1 \mathrm{C}$, applied in the GHS and Packing Groups I, II and III applied in the UN Model Regulations for transport of dangerous goods. In the 21st revision of the Model Regulations (UN-TDG 2019) and in the 8th revision of GHS (UN-GHS 2019) the possibility for sub-classification based on in vitro data was introduced. Category 2 is attributed to irritant substances. Category 3 (mild skin irritation) is optional and is available for those authorities that want more than one skin irritation category (e.g., for classifying pesticides).

OECD GD 237 (OECD 2016a) describes waiving principles applicable to mammalian acute toxicity (oral, dermal and inhalation route), eye and skin irritation and skin sensitisation, intended for pesticides, but extendable also to other chemicals, formulations and biological materials. As specified in the OECD GD 237, "In the context of this document, acute toxicity studies refer to those assessing systemic toxicity as well as those assessing local irritation, corrosion or sensitisation".

The Classification and Labelling ( $\mathrm{C}$ and $\mathrm{L})$ categories used are based on visually observable effects in rabbit skin following Draize skin corrosion and skin irritation test [EU test method B.4, equivalent to OECD TG 404 (OECD 2015c)]. However, as for skin corrosion/irritation, validated and accepted in vitro alternatives shall be used to make classification decisions (EC 2017d). This is also confirmed in the GHS Fig. 3.2.1, which reports tiered testing and evaluation of skin corrosion and irritation potential (see line 28f).

For serious eye damage/eye irritation, the classification system involves a tiered testing and evaluation scheme. The criteria themselves for irreversible or reversible eye effects are still based on animal data. On GHS level, the criteria for serious eye damage and eye irritation is currently under revision, and an updated text to include non-animal criteria is expected in the 9th revision of GHS in 2021. A substance or mixture classified as corrosive to skin is deemed to be classified for serious eye damage, to avoid any testing of corrosive substances for eye effects in vivo (ECHA 2017c).

Under REACH (2020g), for Annex VII and Annex VIII the assessment of skin irritation or skin corrosion using an in vitro test is foreseen. Regarding serious eye damage/eye irritation, the basic information requirement is an in vitro study, and a second in vitro study must be considered if the results from the first in vitro study do not allow a conclusive decision on classification for serious eye damage/eye irritation. Annex VIII foresees the assessment of skin irritation using the in vivo test only if the in vitro studies (under Points 8.1.1 and 8.1.2 of Annex VII) are not applicable, or their result(s) not adequate for classification and risk assessment. Same consideration is made for eye irritation. These amendments to Annexes VII and VIII relevant for skin corrosion/ irritation and serious eye damage/eye irritation have been 
made in 2016 (EC 2016), considering the significant scientific progress in the development of alternative test methods for these endpoints. In particular, for both skin corrosion/ skin irritation and serious eye damage/eye irritation, adequate information for the classification and risk assessment of a substance should be obtained in most cases solely on the basis of in vitro studies. For both these endpoints, in vivo studies may still be required in some cases for substances manufactured or imported in quantities of 10 tpy or more. Therefore, Points 8.1 and 8.2 of Annex VIII were amended so that the standard information requirements are now for the in vitro studies, while setting the conditions under which an in vivo study for skin irritation/corrosion and serious eye damage/eye irritation is still required.

Adopted in vitro OECD TGs and corresponding test methods indicated in Regulation 440/2008 (2019b) for skin corrosion/irritation and serious eye damage/eye irritation are reported in Table 2.

For cosmetic ingredients, skin corrosion/skin irritation and serious eye damage/eye irritation should be assessed using the adopted in vitro methods already specified in Regulation 440/2008 (2019b) (Table 2), together with in chemico/ in silico [i.e., (Q)SAR]. Data obtained from the Draize rabbit test (EC B.4, OECD TG 404) should be provided when available if the test was performed before the animal testing ban, or if the data were obtained to be in compliance with other legislations (e.g., REACH). In SCCS/1602/18 (2018) it is further commented that currently available replacement alternatives for serious eye damage/irritation testing cannot identify any mild eye irritancy potential. Additionally, for eye irritation, no validated alternative method fully replacing the in vivo test (OECD TG 405, EC B.5) can be identified. Therefore, two separate decision trees for eye irritation were put forward: (i) a decision tree specific for hazard identification of the neat cosmetic ingredient (to classify irritant vs non-irritant, using physicochemical properties, read-across data, (Q)SAR results and in vitro eye irritation data); (ii) a decision tree for risk assessment of the neat ingredient in its final formulation(s) (i.e., formulation's eye irritancy measured in one or more in vitro eye irritation test(s) vs measured irritancy of a benchmark control, including a confirmatory formulation test with human volunteers).

\section{Photo-induced toxicity}

CLP (2020f) and REACH (2020g) do not specifically ask for photo-toxicity testing and/or labelling requirements. In the most recent SCCS Notes of Guidance (NoG), one in vitro test method, listed in Regulation 440/2008 (2019b) as test method B.41 In vitro 3T3 NRU Phototoxicity Test [equivalent to OECD TG 432 (OECD 2004c)] is indicated as a mandatory in vitro method to assess photo-induced toxicity, when in the exposure assessment (3.3 in NoG) under "functions and uses of cosmetic ingredients" (3.3.1 in $\mathrm{NoG}$ ) of the dossier submitted, it is shown that exposure to sunlight is possible and the chemical structure indicates the possibility of UV absorption (aromatic groups, double bounds, etc.) and a UV spectrum shows UV absorption. If the UV spectrum does not show UV absorption, there cannot be photo-induced toxicity. As waving principles phototoxicity tests should not be performed if the test material absorbs at wavelengths $<313 \mathrm{~nm}$, and absorption at longer wavelengths is insufficient. For all UV-filters, (in Annex VI of Reg 1223/2009) the 3T3 NRU Phototoxicity test, comparing the cytotoxicity of a chemical tested in the presence and in the absence of exposure at a non-cytotoxic dose of ultraviolet/visible (UV/VIS) light (SCCS 2018), is mandatory (section 3.2.6 in NoG).

Apart from the 3T3 NRU PT [EC B.41, OECD TG 432 (OECD 2004c)], a reconstructed human skin model can be used as a second tier in particular in case of false positives in the 3T3 NRU PT to evaluate effects (checking for the solvents used), and the use of in chemico/in silico [i.e., (Q) SAR] is encouraged (SCCS 2018). While, to date, validated in vitro methods for the detection of photo-sensitisation are not yet available, chemicals showing photo-allergic properties are likely to give positive reactions in the 3T3 NRU PT test.

At present, no official guideline-based protocols for photo-irritation and photo-sensitisation testing in vivo have been evaluated (SCCS 2018).

To assess photo-mutagenicity/photo-clastogenicity, several assays have been adapted to a combined treatment of chemicals with UV-Visible light (EC 2003), including: (1) bacterial and yeast mutation assays, (2) tests for detecting clastogenicity, (3) tests for detecting gene mutations in mammalian cells, and (4) tests for detecting aneugenicity in mammalian cells in vitro. Other available tests are: the photoAmes test, the photo HPRT/photo-mouse lymphoma assay, the photo-micronucleus test, the photo-chromosome aberration test and the photo-Comet assay (all to be evaluated on a case-by-case basis) (Brendler-Schwaab et al. 2004). In chemico/in silico methods are also indicated.

There is no requirement for photo-mutagenicity testing when the phototoxicity tests are negative, or if the compounds have a Molar Extinction Coefficient (MEC) below $1000 \mathrm{~L} \mathrm{~mol}^{-1} \mathrm{~cm}^{-1}$ (EFSA 2020).

\section{Mutagenicity/genotoxicity}

According to CLP Regulation (2020f), hazard categories for germ cell mutagens are related to substances that may cause mutations in the germ cells of humans that can be transmitted to the progeny. Since human data are not available, the results obtained with mutagenicity or genotoxicity tests in vitro and in mammalian somatic and germ 
Table 2 Currently available Test Methods in Regulation (EC) No 440/2008 and corresponding OECD Test Guidelines (TGs)

\begin{tabular}{lcc}
\hline Human health endpoint & Test methods/OECD TGs & In vivo/ \\
in vitro
\end{tabular}

Skin corrosion/irritation

Serious eye damage/irritation

Photo-induced toxicity Mutagenicity/Genotoxicity

Acute systemic toxicity
B.46. In vitro skin irritation: reconstructed human epidermis $(\mathrm{RhE})$ test method [equivalent to In vitro OECD TG 439 (OECD 2015f)]

B.40. In vitro skin corrosion: transcutaneous electrical resistance test (TER) [equivalent to In vitro OECD TG 430 (OECD 2015d)]

B.40 Bis. In vitro skin corrosion: Human skin model test [equivalent to OECD TG 431 (OECD In vitro 2016g)]

In vitro Membrane Barrier Test Method (OECD TG 435) (OECD 2015e) In vitro

B.4: Acute Dermal Irritation/Corrosion [equivalent to OECD TG 404 (OECD 2015c)] In vivo

B.47. Bovine Cornea Opacity Permeability (BCOP) Test Method [equivalent to OECD TG 437 In vitro (OECD 2017e)]

B.48. Isolated Chicken Eye (ICE) test method [equivalent to OECD TG 438 (OECD 2018h)] In vitro

B.61. Fluorescein Leakage (FL) Test Method [equivalent to OECD TG 460 (OECD 2017f)] In vitro

Short Time Exposure (STE) Test Method (OECD TG 491) (OECD 2018p) In vitro

Reconstructed human Cornea-like Epithelium (RhCE) Test Method (OECD TG 492) (OECD In vitro 2018q)

Vitrigel-Eye Irritancy Test Method (OECD TG 494) (OECD 2019a) In vitro

In vitro Macromolecular Test Method (OECD TG 496) (OECD 2019b)

B.5: Acute eye irritation/corrosion (equivalent to OECD TG 405 (OECD 2017d))

B.41 In vitro 3T3 NRU Phototoxicity Test [equivalent to OECD TG 432 (OECD 2004c)]

In vitro

In vivo

B.10. Mutagenicity - In vitro Mammalian chromosome aberration test [equivalent to OECD In vitro TG 473 (OECD 2016i)]

B.11. Mutagenicity-In vivo Mammalian bone marrow chromosome aberration test [equiva- In vivo lent to OECD TG 475 (OECD 2016k)]

B.12. Mutagenicity-In vivo Mammalian erythrocyte micronucleus test [equivalent to OECD In vivo TG 474 (OECD 2016j)]

B.13/14. Mutagenicity: Reverse mutation test using bacteria [equivalent to OECD TG 471 In vitro (OECD 1997b)]

B.17. Mutagenicity - In vitro Mammalian cell gene mutation test [equivalent to OECD TG In vitro 476, which has been recently updated and split into TG 476 (OECD 20161 ) and TG 490 (OECD 2016q)]

B.22. Rodent dominant lethal test [equivalent to OECD TG 478 (OECD 2016m)]

In vivo

B.23. Mammalian Spermatogonial Chromosome aberration test [equivalent to OECD TG 483 In vivo (OECD 2016n)]

B.25. Mouse Heritable Translocation [equivalent to OECD TG 485 (OECD 1986), although In vivo almost never requested]

B.39. Unscheduled DNA synthesis (UDS) test with mammalian liver cells in vivo [equivalent In vivo to OECD TG 486 (OECD 1997c)]

B.49. In vitro mammalian cell micronucleus test [equivalent to OECD TG 487 (OECD 20160)] In vitro

B.58. Transgenic Rodent Somatic and Germ Cell Gene Mutation Assays [equivalent to OECD In vivo TG 488 (OECD 2013)]

B.62. In vivo alkaline single-cell gel electrophoresis assay for DNA strand breaks (comet In vivo assay) [equivalent to OECD TG 489 (OECD 2016p)]

B.1 bis. Acute oral toxicity-Fixed dose procedure [equivalent to OECD TG 420 (OECD In vivo 2002a)]

B.1 tris. Acute oral toxicity-Acute toxic class method [equivalent to OECD TG 423 (OECD In vivo 2002b)]

B.2. Acute toxicity (Inhalation) [equivalent to OECD TG 403 (OECD 2009a)] In vivo

B.3. Acute toxicity (Dermal) [equivalent to OECD TG 402 (OECD 2017c)] In vivo

B.52. Acute Inhalation Toxicity-Acute Toxic Class Method [equivalent to OECD TG 436 In vivo (OECD 2009b)]

OECD TG 425 (OECD 2008b) on Acute oral toxicity: up-and-down procedure) In vivo

OECD TG 433 (OECD 2018g) Acute Inhalation Toxicity: Fixed Concentration Procedure In vivo 
Table 2 (continued)

Human health endpoint

Test methods/OECD TGs

In vivo/

in vitro

Skin sensitisation

Repeated dose toxicity

Carcinogenicity

Reproductive/ developmental toxicity

ADME/TK
B.6: in vivo Guinea Pig test method [equivalent to OECD TG 406 (OECD 1992), comprising the Guinea Pig Maximisation Test (GPMT) and the Buehler Test]

B.42. Local lymph node assay (LLNA) [equivalent to OECD TG 429 (OECD 2010b)]

In vivo

B.50. Local lymph node assay: DA [equivalent to OECD TG 442A (OECD 2010c)]

B.51. Local lymph node assay: BrdU-ELISA [equivalent to OECD TG 442B (OECD 2018i)]

B.59: Direct peptide reactivity assay (DPRA) addressing the key event on 'covalent binding to proteins' of the AOP for skin sensitisation [equivalent to OECD TG 442C (OECD 2020b)]

Amino acid Derivative Reactivity Assay (ADRA) [included in OECD TG 442C (OECD 2020b)]

B.60: ARE-Nrf2 Luciferase Test Method (equivalent to OECD TG 442D) (OECD 2018j)

B.71: In vitro skin sensitisation assays addressing the key event on 'activation of dendritic cells' of the AOP for skin sensitisation (equivalent to OECD TG 442E) (OECD 2018k)

B.7. Repeated dose (28 days) toxicity (Oral) [equivalent to OECD TG 407 (OECD 2008a)]

B.8. Repeated dose (28 days) toxicity (Inhalation) [equivalent to OECD TG 412 (OECD 2018d)]

B.9. Repeated dose (28 days) toxicity (Dermal) [equivalent to OECD TG 410 (OECD 1981a)] In vivo

B.26. Sub-chronic oral toxicity test repeated dose 90-day oral toxicity study in rodents [equiva- In vivo lent to OECD TG 408 (OECD 2018c)]

B.27. Sub-chronic oral toxicity test repeated dose 90-day oral toxicity study in non-rodents [equivalent to OECD TG 409 (OECD 1998)]

B.28. Sub-chronic dermal toxicity study 90 -day repeated dermal dose study using rodent spe- In vivo cies [equivalent to OECD TG 411 (OECD 1981b)]

B.29. Sub-chronic inhalation toxicity study 90 -day repeated inhalation dose study using rodent In vivo species [equivalent to OECD TG 413 (OECD 2018e)]

B.30. Chronic Toxicity test [equivalent to OECD TG 452 (OECD 2018n)]

B.33. Combined Chronic Toxicity/Carcinogenicity Studies [equivalent to OECD TG 453 (OECD 20180)]

B.38. Delayed neurotoxicity of organophosphorus substances 28 day repeated dose study In vivo [equivalent to OECD TG 419 (OECD 1995)]

B.43. Neurotoxicity study in rodents [equivalent to OECD TG 424 (OECD 1997a)] In vivo

Combined repeated dose toxicity study with the reproduction/developmental toxicity screening In vivo test (OECD TG 422) (OECD 2016f)

B.32. Carcinogenicity test [equivalent to OECD TG 451 (OECD 2018m)]

B.33. Combined chronic toxicity/Carcinogenicity test [equivalent to OECD TG 453 (OECD 20180)]

B.21. In vitro Mammalian cell transformation test

B.31. Prenatal developmental toxicity Study [equivalent to OECD TG 414 (OECD 2018f)]

B.35. Two-Generation Reproduction toxicity Study [equivalent to OECD TG 416 (OECD 2001)]

B.53. Developmental Neurotoxicity study [equivalent to OECD TG 426 (OECD 2007a)]

B.54. Uterotrophic Bioassay in rodents [equivalent to OECD TG 440 (OECD 2007b)]

B.55. Hershberger bioassay in rats [equivalent to OECD TG 441 (OECD 2009c)]

B.56. EOGRTS [equivalent to OECD TG 443 (OECD 20181)]

OECD TG 421 (Reproduction/Developmental Toxicity Screening Test) (OECD 2016e)

OECD TG 422 (Combined Repeated Dose Toxicity Study with the Reproduction/Developmental Toxicity Screening Test) (OECD 2016f)

B.36. Toxicokinetics [equivalent to OECD TG 417 (OECD 2010a)]

B.44. Skin absorption: In vivo method [equivalent to OECD TG 427 (OECD 2004a)]

B.45. Skin absorption: In vitro method [equivalent to OECD TG 428 (OECD 2004b)]
In vivo

In vivo

In vitro

In vivo

In vivo

In vivo

In vivo

In vivo

In vivo

In vivo

In vivo

In vivo

In vivo

In vitro 
cells in vivo are used in classifying substances and mixtures within this hazard class. Category 1 (accounting for subcategories $1 \mathrm{~A}$ and $1 \mathrm{~B}$ ) identifies substances known to induce heritable mutations (Cat $1 \mathrm{~A}$ ) or to be regarded as if they induce heritable mutations in the germ cells of humans (Cat 1B). Category 2 applies to substances that may induce heritable mutations in the germ cells, therefore causing concern for humans.

For a comprehensive coverage of the potential mutagenicity of a substance, information on gene mutations (base substitutions and deletions/additions), structural chromosome aberrations (breaks and rearrangements, defined as clastogenicity) and numerical chromosome aberrations (loss or gain of chromosomes, defined as aneuploidy) is required (EC 1223/2009) (EC 2020e; ECHA 2017b).

Under REACH $(2020 \mathrm{~g})$, the assessment of mutagenicity follows a stepwise approach, which starts with a battery of in vitro tests, followed up by appropriate in vivo testing in case one or more of the in vitro tests are positive. The in vitro studies for mutagenicity include an in vitro gene mutation study in bacteria (Ames test), an in vitro cytogenicity study in mammalian cells (i.e., an in vitro chromosome aberration study or an in vitro micronucleus study) and, if both in vitro tests are negative, an in vitro gene mutation study in mammalian cells should be performed. If there is a positive result in any of the above in vitro studies and there are no results available from an appropriate in vivo study already, an appropriate followup in vivo study in somatic cells must be proposed by the registrant. In some cases, a second in vivo somatic cell test may be necessary depending on the quality and relevance of all available data. If there is a positive result from an in vivo somatic cell study, the potential for germ cell mutagenicity should be considered on the basis of all available data, including TK information (if available). Moreover, as for any other endpoint under REACH, the information required for a substance depends on its volume (tpy) of production or importation.

Several in vitro and in vivo test methods and OECD TGs for mutagenicity and genotoxicity are indicated in Regulation (EC) No 440/2008 (2019b), as summarised in Table 2.

To assess the potential for mutagenicity of a cosmetic substance (EC 1223/2009) (EC 2020e), two tests in particular are recommended: the Bacterial Reverse Mutation Test, Ames (OECD TG 471) (OECD 1997b), to assess gene mutations, and the In vitro Micronucleus Test (OECD TG 487) (OECD 2016o), to assess both clastogenicity and aneugenicity.

In cases where the bacterial reverse mutation test is not suited, as in the case of nanoparticles, a revised genotoxicity test battery, which includes in vitro mammalian cell mutagenicity and clastogenicity assessments, has been recommended (Elespuru et al. 2018).
If the results from both tests are clearly negative in adequately performed tests, it is very likely that the substance has no mutagenic potential. Likewise, if the results from both tests are clearly positive, it is very likely that the substance has mutagenic potential. In both cases, further testing is not necessary. If one of both tests is positive, the substance is considered an in vitro mutagen, and further in vitro testing is needed to exclude the potential mutagenicity of the substance under investigation. A toolbox for the evaluation in a Weight-of-Evidence (WoE) approach has been proposed in the SCCS/1602/18 (2018), which includes among others: the comet assay in mammalian cells, comet or micronucleus assay on 3D-reconstructed human skin, the Hen's Egg test for Micronucleus Induction (HET-MN), mechanistic investigations (e.g., toxicogenomics) or internal exposure (TK), Reporter gene assays based on human, animal or bacterial cells (Pfuhler et al. 2020). For chemicals that are primarily associated with dermal exposure, the use of reconstructed human skin models has been explored and protocols have been developed for a reconstructed skin micronucleus test (RSMN) (Curren et al. 2006; Mun et al. 2009) and a RS Comet assay (i.e., 3D Skin Comet) (Reisinger et al. 2018) based on the best suited skin tissues (Curren et al. 2006; Pfuhler et al. 2011; Reisinger et al. 2018). The development of OECD test guidelines based on these tests is currently ongoing.

\section{Acute systemic toxicity}

In the Regulation (EC) No 1272/2008 (CLP) (2020f), acute toxicity hazard categories and acute toxicity estimates defining the respective categories are based on animal data, while categories for specific target organ toxicity after single exposure are based on evidence from humans and/or from experimental animals. Animal studies to assess adverse effects and $\mathrm{LD}_{50}$ or $\mathrm{LC}_{50}$ value of tested compounds (which may result from a single exposure, usually carried out with high doses of the test substance), are thought to allow determination or estimation of a range of severe acute toxic effects including mortality. Substances can be allocated to one of four toxicity categories based on acute toxicity by the oral, dermal or inhalation route according to the numeric criteria.

Under REACH (2020g), and as described in the ECHA Guidance (2017b), the assessment of acute systemic toxicity is among the standard information requirements for substances manufactured or imported into the EU in quantities of 1 tonne or more per year (tpy), and standard information requirements are specified in Annexes VII and VIII. Acute toxicity testing is not required if the substance is corrosive to the skin. In particular, as indicated under Annex VII ( $\geq 1$ tpy), acute toxicity study(ies) via the oral route of exposure is(are) required, and waiving is allowed if a study on acute toxicity by the inhalation route is available. For 
substances manufactured or imported into the EU in quantities of $\geq 10$ tpy (under Annex VIII), in addition to acute toxicity study(ies) via the oral route of exposure, information on at least one other route of exposure is requested, depending on the nature of the substance and the likely route of human exposure. As described in Column 2 of section 8.5.3 of Annex VIII, waiving of acute dermal toxicity testing is further allowed if: (i) the substance does not meet the criteria for classification for acute toxicity or STOT-SE (specific target organ toxicity-single exposure) by the oral route, and (ii) no systemic effects have been observed in in vivo studies with dermal exposure (e.g., skin irritation, skin sensitisation) or, in the absence of an in vivo study by the oral route, no systemic effects after dermal exposure are predicted on the basis of non-testing approaches [e.g., read across, (Q) SAR studies]. In line with this, WoE-based adaptation to the standard information requirement may be adopted for acute oral toxicity studies, particularly for substances to be registered at Annex VIII tonnage level and above (i.e., registrations at $>10$ tpy), for which an oral sub-acute toxicity study (OECD TG 407) (OECD 2008a) or the combined repeated dose toxicity study with the reproduction/developmental toxicity screening test (OECD TG 422) (OECD 2016f) is required. This WoE adaptation proposed by ECHA (ECHA 2017b) applies to low toxicity substances (i.e., those that are not to be classified for acute oral toxicity). Further considerations regarding these adaptation rules are also discussed in Buesen et al. 2018; Gissi et al. 2017, 2018; Graepel et al. 2016.

According to the ECHA Guidance (2017b), derivation of $\mathrm{LD}_{50}$ or $\mathrm{LC}_{50}$ values is no longer considered essential. Indeed, some of the current standard acute systemic toxicity TGs [e.g., EU B.1 bis/OECD TG 420 (OECD 2002a) and OECD TG 433 (OECD 2018g)], use signs of non-lethal toxicity (rather than mortality). These test methods should be preferred as they present advantages over the other guidelines in terms of animal welfare.

Recommended test methods, as indicated in Regulation (EC) No 440/2008 (2019b), and corresponding OECD TGs for acute systemic toxicity are summarised in Table 2.

As per Regulation (EC) No 1223/2009 (Cosmetic Products Regulation) (2020e), acute systemic toxicity plays in practice a limited role for the cosmetics industry. Ingredients used in this sector essentially do not raise the risk of acute systemic toxicity and sufficient information is often available from repeated dose studies if conducted before 2013 . Additionally, any possible impacts on the toxicological profile due to particle sizes, including nanomaterials, impurities of the substances and raw material used, and interaction of substances should be considered, and validated alternative non-animal methods applied.

According to the Notes of Guidance SCCS/1602/18 (2018), validated (animal-free) replacement methods for acute systemic toxicity are not available. However, data on acute systemic toxicity are not mandatory for assessing the safety of cosmetic ingredients for consumer uses. A WoE approach [e.g., data from chemical grouping/read-across, (Q)SAR, in vitro studies, or repeated dose toxicity studies] may be sufficient to drive conclusions on the safety of cosmetic products for acute systemic toxicity.

As already mentioned under "Skin corrosion and irritation and serious eye damage/eye irritation" section, OECD GD 237 opens the possibility to waive animal studies where the results of validated in vitro tests or alternative approaches are adequate to draw a conclusion regarding the classification of an acute hazard for a test chemical. These waiving principles are applicable to mammalian acute toxicity (oral, dermal and inhalation route), eye and skin irritation and skin sensitisation, and although they were mainly intended for pesticides, they can be extended to other chemicals, formulations and biological materials. The approaches outlined in OECD GD 237 should be used by regulatory jurisdictions as part of the WoE to determine the need for a mammalian acute toxicity study and establish appropriate classification and/or labelling.

\section{Skin sensitisation}

Assessment of categories and subcategories for skin sensitisers under CLP (2020f) is done considering evidence derived from effects seen in humans and/or animal tests. Skin sensitisers are classified as Category 1 . If data allow, optional subcategorisation of sensitisers into subcategories 1A (strong sensitisers) and 1B (other skin sensitisers) can be performed. As a general comment, when considered in the context of a WoE approach, evidence from animal studies is usually more reliable than evidence from human exposure, since the latter is usually derived under less controlled studies. Human evidence may derive from clinical experience, diagnostic patch testing, and other tests designed to confirm the absence of sensitisation potential under expected exposure conditions. Human tests for the purpose of hazard identification are not conducted in the EU because considered unethical.

REACH information requirements for skin sensitisation have been recently revised [Section 8.3 of Annex VII, as of May 2017 (EC 2017a)] and this information should come from: (i) in vitro/in chemico data addressing the three key events (KEs) described in the skin sensitisation Adverse Outcome Pathway (AOP) (i.e., molecular interaction with skin proteins, inflammatory response in keratinocytes, activation of dendritic cells) (Landesmann and Dumont 2012; OECD 2012); and (ii) an in vivo study, normally a Local Lymph Node Assay (LLNA) [described in OECD TG 429 (OECD 2010b)], in case the in vitro/in chemico studies are not applicable for the substance, or are not adequate for 
classification and risk assessment. In case a substance is considered a skin sensitiser, the revised REACH requirements also introduce the need to assess whether it can be presumed to have the potential to produce significant sensitisation in humans (i.e., GHS /CLP Cat. 1A).

The ECHA guidance document (ECHA 2017b) for this endpoint has been revised to inform about the recent adoption or revision of several EU test methods and/or OECD TGs for skin sensitisation. Additionally, information about the use of non-testing data has been updated to reflect ECHA's current approach to dossier evaluation. The testing and assessment strategy for skin sensitisation has also been updated, and now it foresees the use of non-animal test methods addressing AOP KEs for generating adequate information. According to Annex VI, the registrant should gather and evaluate all existing available information before considering further testing. This includes structural considerations, physico-chemical properties, $(\mathrm{Q}) \mathrm{SAR}$, information from structurally similar substances, in vitro/in chemico data, animal studies, and human data. For classified substances, information on exposure, use and risk management measures should also be collected and evaluated to ensure that potential risks are identified and adequate risk management measures are taken.

The in vivo and in vitro test methods (and OECD TGs) for skin sensitisation (Regulation 440/2008 (2019b)) are summarised in Table 2. In particular, B.71: In vitro skin sensitisation assays (equivalent to OECD TG 442E) addresses the activation of dendritic cells, one KE in the AOP for skin sensitisation (Landesmann and Dumont 2012; OECD 2012), and provides three in vitro test methods addressing mechanisms under the same KE: (i) the human Cell Line Activation Test (or h-CLAT method), (ii) the U937 Cell Line Activation Test (or U-SENS), and (iii) the Interleukin-8 Reporter Gene Assay (or IL-8 Luc assay).

For testing of cosmetics ingredients, skin sensitisation is considered among the most relevant endpoints due to the high frequency of allergic reactions among the undesirable effects of cosmetic products. Notably, recent efforts have been made by the cosmetic industry to develop a non-animal, next generation risk assessment (NGRA) framework for the assessment of skin sensitisers (Gilmour et al. 2020).

\section{Repeated dose toxicity}

According to the CLP Regulation (2020f), categories for specific target organ-toxicity-repeated exposure are based on evidence from humans (although rarely available) and/or from in vivo laboratory animal studies. Under REACH, the standard information requirements for repeated dose toxicity are in vivo studies (in rats) of increasing minimum duration as the tonnage band increases. The oral route is the most common, but substance properties and the relevant exposure route for humans need to be taken into account. The standard information requirements on repeated dose toxicity are specified in REACH Annexes VIII-X. Information on a subacute (28-day) study is needed at Annex VIII (10-100 tpy) level. At the next tonnage band, a longer study, i.e., subchronic (90-day) study, is required. In addition, further studies may be needed at Annex levels IX and X to address concerns related to longer exposure duration, different route of administration and/or specific toxicological investigations, such as immunotoxicity or neurotoxicity. Long-term chronic toxicity studies may be needed based on human exposure considerations. In the context of REACH, the benchmark dose [BMD, defined as the dose corresponding to a 'specific change in an adverse response compared to the response in unexposed subjects' (Dakeishi et al. 2006)] may also be used, and species-specific information, e.g., on respiration rates and body weight, enable extrapolation between studies with different exposure routes.

Importantly, the ECHA Guidance (2017b) describes the use of an Integrated Testing Strategy (ITS) for repeated dose toxicity. In particular, testing for repeated dose toxicity is not required for chemicals produced at tonnage levels less than 10 tpy, whilst at higher production volumes, standard data requirements are increased with each tonnage.

As indicated in Regulation (EC) No 440/2008 (2019b), current standard test methods and corresponding OECD TGs are all in vivo studies (Table 2).

As outlined in both Regulation (EC) No 1223/2009 (Cosmetic Products Regulation) (2020e) and SCCS/1602/18 (2018), evaluation of systemic toxicity is a key element for cosmetic ingredients, which are repeatedly in contact with human skin and mucosa. If studies of only 28-day duration are available, a default assessment factor of three to extrapolate from subacute ( 28 days) to subchronic ( 90 days) toxicity may be used in the calculation of the Margin of Safety (MoS), as also applied under REACH (ECHA 2012). The inhalation route is only rarely used in repeated dose toxicity testing of cosmetic ingredients, unless a cosmetic product is intended to be used in an aerosolised, sprayable, or powdered form. If the dose regimen of a study was 5-day treatment per week, the derived dose-descriptor corrected by a factor of 5/7 is normally used. SCCS recognises that the BMD can be used as an alternative to the No Observed Adverse Effect Level (NOAEL) approach for deriving a Point of Departure (PoD), which is defined as the point on a toxicological dose-response curve corresponding to an estimated low effect level or no effect level (ChemSafetyPro 2018). The 28-day and 90-day oral toxicity tests in rodents are the most commonly used repeated dose toxicity tests. Preferably, studies of 90 days or more should be used in safety assessments. In a number of cases, dermal repeated dose toxicity studies are present among the submitted data 
for the cosmetic ingredients listed in Annexes III-VI of Cosmetic Products Regulation, as for example in the case of UV-filters.

\section{Carcinogenicity}

Under CLP (2020f), hazard categories for carcinogens are largely based on human (if available) and/or animal evidence. Category 1 accounts for known or presumed human carcinogens on the basis of epidemiological and/or animal data. A substance may be further distinguished as category 1A (i.e., carcinogenic potential for humans, based on human evidence), or category 1B (i.e., presumed carcinogenic potential for humans, based on animal evidence). Category 2 is assigned to suspected human carcinogens, and this classification is done on the basis of evidence obtained from human and/or animal studies, which is not convincing enough to place the substance in Category 1A or 1B.

REACH (2020g) requires a carcinogenicity test for substances falling under Annex X ( $\geq 1000$ tpy), in case: (i) of widespread dispersive use, or when there is evidence of frequent or long-term human exposure, and (ii) if the substance is classified for mutagenicity (germ cell mutagen category 3 under CLP, now category 2), or there is evidence from the repeated dose study(ies) that the substance is able to induce hyperplasia and/or pre-neoplastic lesions.

If the substance is classified as mutagen category $1 \mathrm{~A}$ and $1 \mathrm{~B}$, the default presumption would be that a genotoxic mechanism for carcinogenicity is likely. In these cases, a carcinogenicity test will normally not be required, according to the standard information requirement (Annex X).

Proposals for conducting a carcinogenicity test should be made with regard to the potential risk to human health and with consideration of the actual or intended production and/or use pattern. However, REACH also requires that carcinogenic substances at all tonnage levels be identified as substances of high concern, taking into account information from all available relevant sources (non-human and human, non-testing and testing data), which can inform on hazard identification, underlying modes of action or carcinogenic potency. In addition, the classification and labelling as listed in Annex VI of CLP Regulation is legally binding and can trigger further assessment under REACH to decide if the substance should be formally identified as a substance of very high concern (SVHC) (Madia et al. 2016).

The ECHA Guidance (2017b) proposes a testing strategy entailing the following three steps for the assessment of carcinogenicity for substances at each of the tonnage levels specified in Annexes VII to X of REACH: (i) gather and assess all available test and non-test data from readacross and/or proper chemical category (chemical grouping) and suitable predictive models, and examine the WoE that relates to carcinogenicity; (ii) consider whether the standard information requirements are met; (iii) ensure that the information requirements of Annexes VII and VIII are met, and make proposals to conform to Annexes IX and $\mathrm{X}$ (whether further tests are needed to fulfil requirements under Annexes IX and X).

In case a carcinogenicity study needs to be conducted, a testing proposal needs to be submitted to the agency as specified in REACH. For substances at annex X, predictive techniques, such as chemical grouping and read-across, and the use of (Q)SARs may be supplemented with in vitro or alternative shorter-term in vivo studies to circumvent the need for a carcinogenicity study (ECHA 2017b).

Different sources of information may enable drawing inferences regarding the potential of a chemical to be carcinogenic to humans. In particular, non-human data, including non-testing data, testing data (both in vitro and animal), human data, and information on exposure, use and risk management should be considered (paragraph R.7.7.10, Information sources on carcinogenicity) (ECHA 2017b).

In the Regulation (EC) No 440/2008 (2019b), two in vivo tests are described: B.32. Carcinogenicity test [equivalent to OECD TG 451 (OECD 2018m)], and B.33. Combined chronic toxicity/Carcinogenicity test [equivalent to OECD TG 453 (OECD 20180)], and one in vitro test: the B.21. In vitro Mammalian cell transformation test (see Table 2). At present, no validated (animal-free) replacement methods included in OECD TGs to study carcinogenicity are available.

As for industrial chemicals under REACH, also for cosmetics ingredients, genotoxicity information is the main driver for consideration of carcinogenicity.

Two OECD Guidance Documents (GDs) on in vitro Cell Transformation Assays (CTA) have been adopted: CTA in Syrian Hamster Embryo (SHE) cells performed at pH 6.7 and at pH 7.0 (OECD GD 214) (OECD 2015b), and CTA in Bhas 42 cell line (OECD GD 231) (OECD 2016b).

As suggested in the SCCS Notes of Guidance (SCCS 2018), a positive result in one of the in vitro genotoxicity tests may be indicative to consider a substance as a putative carcinogen. This indication may be further supported by a positive result in cell transformation assays. However so far, there are no specific requirements to obtain information on non-genotoxic carcinogenicity as such, and many non-genotoxic carcinogens may remain unidentified (Jacobs et al. 2016). According to the SCCS Notes of Guidance (SCCS 2018), also in vitro toxicogenomics can be used in a WoE approach, especially for the detection of non-genotoxic carcinogens. CTA in combination with other existing information and toxicogenomics approaches may be considered as part of integrated approaches to testing and assessment (IATA). Further information on the status of 
in vitro carcinogenicity testing can be found in (Adler et al. 2011; Jacobs et al. 2020; Madia et al. 2014, 2016; Worth et al. 2014).

\section{Reproductive and developmental toxicity}

CLP criteria for hazard categories for reproductive toxicants are either based on evidence from humans (rarely available) and/or data from animal studies (2020f). Category 1A is assigned to known human reproductive toxicants based on evidence in humans, and category $1 \mathrm{~B}$ is assigned to chemicals that are presumed human reproductive toxicants based on data from animal studies. When there is mechanistic information that raises doubt about the relevance of the effects for humans, classification in Category 2, which identifies suspected human reproductive toxicants, may be considered more appropriate. Moreover, classification as a reproductive toxicant is made on the basis of a WoE assessment, i.e., all available information is considered together. This information may be derived from epidemiological studies and case reports in humans and specific reproduction studies in animals that investigate fertility, sexual function and developmental effects in offspring along with subchronic, chronic and special studies in animals that provide relevant information regarding toxicity to reproductive and related endocrine organs.

Under REACH (2020g), the reproductive toxicity of a substance is primarily assessed by means of three different studies: (i) a reproduction/developmental toxicity screening test (e.g., OECD TG 421/422), (ii) prenatal developmental toxicity studies in two species, and (iii) an extended one-generation reproductive toxicity study (EOGRTS). It should be considered that at Annex VII, none of these tests need to be provided, while at Annex VIII, a screening study is required as a minimum, with the proposal to consider performing a prenatal developmental toxicity study if there are any indications of concern for this endpoint from existing information. The EOGRTS would normally only be required at Annex $\mathrm{X}$ but could be triggered at lower tonnages (Annexes VIII or IX) on the basis of concerns of potential adverse effects from existing information. Theoretically, in exceptional cases, information from an EOGRTS in a second species or strain may be legally required at Annex X.

The EOGRTS [EC B.56, OECD TG 443 (OECD 20181)] is now considered the information requirement for reproductive toxicity instead of the two-generation reproductive toxicity study [EC B.35, OECD TG 416 (OECD 2001)] based on an amendment from 2015 (Commission Regulation (EU) 2015/282) (EC 2015a). Although a two-generation reproductive toxicity study is accepted to cover the standard information requirement, instead of an EOGRTS, if initiated before March 13, 2015. EOGRTS offers a number of advantages in comparison to the two-generation reproductive toxicity study, as it assesses a greater number of animals of the first filial generation (F1) and addresses additional parameters, improving the sensitivity and level of information that can be obtained from the test, and may allow a reduction of the number of animals to be used (depending on the study design). The standard information requirement in Annexes IX and X should be limited to the basic configuration of EOGRTS (without extension to include an F2 generation).

Nevertheless, in certain specific cases, where justified, the registrant should be able to propose and ECHA should be able to request the performance of the F2 generation (e.g., on the basis of concerns for endocrine disruption), as well as the developmental neurotoxicity (DNT) and developmental immunotoxicity (DIT) cohorts. DNT and DIT are regarded as important and relevant developmental toxicity endpoints, which could be further investigated. However, analysing the DNT and DIT cohorts entails significant additional costs as well as subjecting animals to additional experiments. Currently, analysis of DIT and/or DNT cohorts is only requested subject to specific concern-driven triggers (see "Developmental neurotoxicity (DNT)" and "Immunotoxicity and developmental immunotoxicity (DIT)" sections).

In REACH, studies on reproductive and developmental toxicity are required from Annex VIII through Annex X, and the standard information requirements are cumulative (i.e., requirements at higher tonnage levels add to the information requirements at lower tonnage levels). If a substance is known to have an adverse effect on fertility, meeting the criteria for classification as Repr Cat $1 \mathrm{~A} / 1 \mathrm{~B}$, and the available data are adequate to support a robust risk assessment, then no further testing for sexual function and fertility will be necessary. However, testing for developmental toxicity must be considered. With regard to substances known to cause developmental toxicity and classified as Repr Cat 1A/1B, no further testing for developmental toxicity will be necessary, although testing for effects on fertility must be considered. In cases where there are serious concerns about the potential for adverse effects related to fertility or development, the registrant may propose an EOGRTS (Annex IX, Section 8.7.3) and/or a pre-natal developmental toxicity study (Annex IX, Section 8.7.2), as appropriate, instead of the screening study to address the concern(s). If there are no adverse effects leading to a concern for development, a prenatal developmental toxicity study may not be used to fulfil the requirement for a reproductive screening study.

The ECHA Guidance (ECHA 2017b) further comments on the applicability of an ITS for reproductive toxicity, which is defined as an approach that combines one or more non-animal methods with animal studies to fulfil the information requirements, or could include only non-animal methods if they together covered all key aspects of reproductive toxicity. However, the use of non-animal methods should be assessed on a case-by-case manner, ensuring that 
the obtained results cover all of the key aspects of reproductive toxicity and are suitable for both risk assessment (e.g., derivation of NOAEL) and classification and labelling.

Table 2 summarises the test methods (Regulation 440/2008 (2019b)) and corresponding OECD TGs suitable to assess reproductive and developmental toxicity.

With regard to cosmetic ingredient safety assessment, the one or two-generation reproduction toxicity test (or the EOGRTS) were the most commonly performed in vivo reproductive toxicity studies before the animal testing ban.

Three alternative embryotoxicity-related methods are currently available: (1) the Whole Embryo Culture test (WEC), (2) the MicroMass test (MM), and (3) the Embryonic Stem cell Test (EST), which can all be used to identify strong embryotoxic substances (Balls and Hellsten 2002; Spielmann et al. 2006). At OECD level, a detailed review paper on "Pluripotent stem cell assays: Modalities and applications for predictive developmental toxicity" is currently under development.

Other in vitro methodologies, covering male and female fertility, implantation and pre- and postnatal development have been and are being developed, such as under ReProTect (http://www.reprotect.eu/) or the EURION cluster (https:// eurion-cluster.eu/2. It should be considered that, to date, validated animal-free methods accepted as a full replacement are not available (Adler et al. 2011; Worth et al. 2014), and that the available alternative methods are not able to mimic all of the various developmental stages, therefore a battery of tests will be needed. However, a more radical change towards next generation risk assessment may allow to move away from prediction of current toxicity classes to prediction of likely safe doses, as indicated in the OECD GD 275 (OECD 2017a).

\section{Absorption, distribution, metabolism and excretion (ADME) and toxicokinetics (TK)}

Information on the biological fate of a chemical in the body plays an important role in human safety assessment. While there are few explicit requirements in EU chemicals legislation for the generation of TK data (i.e., in vitro, in vivo measurements or computational predictions), the use of these data to support the assessment of systemic toxicity is widely recommended in regulatory guidance, although not consistently required in regulations (Bessems et al. 2015). For instance, ADME/TK information is required under the Biocidal Products (Regulation (EU) No 528/2012) (EC 2012) and Plant Protection Products [Regulation (EC) No 1107/2009 (EC 2009) and Commission Regulation (EU) No 283/2013 (EC 2013b)] (which are out of the scope of this document), and the EU Plant Protection regulation also requires the generation of human in vitro biotransformation data to compare with rodent data and studies. However, this is not the case for other regulations as briefly explained.

There are no CLP categories for TK and the CLP Regulation does not specifically require the assessment of ADME and TK (2020f). However, ADME and TK data may be used in a WoE approach to classify, lower the classification or abstain from classification for a particular toxicodynamic (TD) endpoint. For the classification of substances as carcinogens, all available information regarding the physicochemical, TK and TD properties of the substances, as well as information on structure activity relationships, should be taken into account to undertake classification.

Under REACH $(2020 \mathrm{~g})$, TK studies in vivo are not required; however, all available information should be provided, including TK information. Importantly, human health hazard assessment shall consider ADME and TK of substances. Even though TK is not a toxicological endpoint and is not specifically required by $\mathrm{REACH}$, the generation of TK information can help interpret data, assist testing strategy and study design, as well as category development, thus helping to optimise test designing. Furthermore, under REACH, TK data would be very useful for assessing readacross and categories, but as this is not a standard information requirement, that information is rarely available.

The ECHA Guidance (ECHA 2017b) reports many examples of recommendations on the use of TK data that would replace default assessment factors (e.g., Sections R.7.12 and R.8.4 in Chapters R.7.C and R.8, respectively). The guidance highlights that TK studies may be helpful in the evaluation and interpretation of repeated dose toxicity data (e.g., in relation to accumulation of a substance or its metabolites in certain tissues or organs), as well as in relation to mechanistic aspects of repeated dose toxicity and species differences. TK information can also assist in the selection of the dose levels. A very important observation is that TK and potential TD properties based on available data should be considered before undertaking animal tests. Understanding these properties will enable the design of appropriate protocols for the standard tests to be developed, especially with respect to tissue(s) to be investigated, the route of substance administration and the highest dose to be tested. If there is poor understanding of the systemic availability of a test substance, TK investigations or modelling may be necessary.

The three following test methods (and corresponding OECD TGs) for TK are indicated in Regulation 440/2008 (2019b): B.36. Toxicokinetics (in vivo) [equivalent to OECD TG 417 (OECD 2010a)], B.44. Skin absorption: In vivo method [equivalent to OECD TG 427 (OECD 2004a)], and B.45. Skin absorption: In vitro method [equivalent to OECD TG 428 (OECD 2004b)] (Table 2). These EU test methods and OECD TGs generate data for $\mathrm{TK}$, and currently most of them are based on animal procedures as the traditional approach of obtaining whole-body 
TK parameters. However, by exploiting modern developments in predictive toxicology, there are increasing opportunities to generate human-relevant whole-body TK information using physiologically based kinetic (PBK) models (Paini et al. 2019).

These mathematical models, which represent the body as a set of interconnected compartments linked by blood flow, would enable not only the generation of TK data, but also the integration of human data generated by in silico and in vitro methods for ADME. The lack of standardisation of such methods hampers their regulatory acceptance and use (Bessems et al. 2015). However, there is an on-going international effort at OECD to promote the regulatory use of PBK models based on in silico and in vitro data and body physiological parameters (Sachana 2019).

In relation to cosmetic ingredients, information on TK parameters (e.g., human systemic and dermal exposure, and biotransformation) is recommended (EC 2020e). In particular, with regard to dermal/percutaneous absorption and in specific cases, data from in vivo studies that have been carried out before the animal testing ban, or data from in vitro biotransformation studies are required (SCCS 2018), to prove or to exclude certain adverse effects (e.g., EC B.44, 45; OECD TG 427, TG 428). For dermal absorption, it should be considered whether the formulation can affect compound bioavailability.

With regard to in vitro dermal absorption of cosmetic ingredients, some basic criteria have been provided when performing in vitro dermal absorption studies, along with rules to follow in case no dermal absorption studies are available (e.g., regarding the amounts to be applied and what to do in case the basic criteria have not been followed) (SCCS 2010).

For substances with very low dermal absorption and limited permeation (such as colourants or UV-filters with high molecular weight and low solubility), the epidermis may be excluded as a route of entry (WHO 2006). For nanomaterials, it should be ascertained whether the substance absorbed through the skin is in nanoparticle form or in a dissolved chemical state.

Besides the determination of TK parameters of the parent chemical, it is also essential to obtain accurate profiles of metabolites that could be more potent than the parent compound. Cells and cell fractions or organ specimens from human sources, although limited, are available, together with 3D cultures to preserve metabolic capacity and regulation of xenobiotic metabolising enzymes. Additionally, the use of-to-in vivo extrapolation (IVIVE) and PBK modelling is encouraged to translate external exposures into an internal (target) dose in the body and vice versa (Yoon et al. 2012). PBK models are increasingly being used to aid: (i) extrapolation within and between species (variability issues), (ii) route-to-route, (iii) dose extrapolation, and (iv) replacement of default assessment factors by more specific, substancederived factors.

\section{Toxicity effects for which there are currently no direct information requirements}

Apart from the major endpoints described above, current EU regulations do not specifically address more physiologically complex toxicity effects, such as DNT, immunotoxicity and DIT, and endocrine disruption. For instance, according to REACH, neurotoxicity and immunotoxicity studies are only required when concern-driven scientific triggers are observed. On the other hand, with regard to cosmetic ingredients, there are no requirements for the assessment of these effects, or, such effects could be assessed using in vitro tests when needed.

\section{Developmental neurotoxicity (DNT)}

In light of the increasing prevalence of cognitive defects in children [e.g., about 1 in 59 children has been identified with some form of autism (CDC 2018)], it is of pivotal importance to develop better testing strategies to evaluate chemicals for their potential to cause DNT. Current strategies to screen chemicals for their potential to induce DNT are based on animal testing, since there are no regulatory accepted non-animal methods for this purpose. Moreover, testing of DNT for regulatory purposes is not a standard requirement within the EU, and DNT testing [OECD TG 426 (OECD 2007a)] is only performed when triggered based on structure activity relationships or evidence of neurotoxicity in systemic adult studies, such as those associated with repeated dose toxicity and reproductive and developmental toxicity (e.g., 28- and 90-day repeated dose toxicity studies, or the EOGRTS). However, there are intrinsic limitations in this approach. For instance, DNT studies are not often performed upon triggers, and this is often due to their time and overall cost (Rovida and Hartung 2009; Tsuji and Crofton 2012). Additionally, triggers of DNT studies may not represent reliable indicators of DNT, as repeated dose toxicity and reproductive and developmental toxicity studies are conducted in adult animals. In fact, the OECD TG 426 has been used to assess the effects of a limited number of pesticides and industrial chemicals (about 120) (Crofton et al. 2012; Kadereit et al. 2012; van Thriel et al. 2012). For these reasons, only a very limited amount of chemicals has been screened and identified as developmental neurotoxicants (Bjorling-Poulsen et al. 2008; Grandjean and Landrigan 2006; Smirnova et al. 2014), and alternative methodologies suitable to more rapidly and cost-effectively screen large numbers of chemicals for their potential to cause DNT in humans are dearly needed (Bal-Price et al. 2018). 
It is currently considered that a battery of alternative in vitro methods suitable to capture several key neurodevelopmental processes, combined with in silico approaches [(Q)SAR, read-across, computational modelling] and nonmammalian animal models (e.g., zebrafish, medaka or C. elegans) may pave the way to a more efficient DNT testing (Bal-Price and Fritsche 2018). Under the umbrella of the OECD, an international partnership (EFSA, US EPA, academia, etc.) is currently developing a strategy to enhance regulatory DNT testing using a battery of in vitro assays mainly applied to human neuronal/glial models derived from induced pluripotent stem cells. These in vitro assays are anchored to critical neurodevelopmental processes and KEs identified in DNT AOPs, to gather mechanistic understanding for the development of an IATA. These activities will support the development of an OECD guidance document on the use of alternative methods for DNT testing, including guidance on data interpretation (Sachana et al. 2019).

\section{Immunotoxicity and developmental immunotoxicity (DIT)}

As for DNT, specific information about immunotoxicity and DIT outside the information provided by the general systemic in vivo test methods is not normally required for industrial chemicals or cosmetic ingredients, and the triggers of further testing are considered on a case-by-case basis. Repeated dose toxicity and reproductive and developmental toxicity studies should be performed in a way that allows evaluation of immunotoxicity and/or DIT (e.g., an EOGRTS may be conducted including the immunotoxicity cohort). More specifically, in OECD TG 443 (EOGRTS) (OECD 20181) it is also specified that 'decisions on whether to assess the second generation and to omit the (DNT) cohort and/or (DIT) cohort should reflect existing knowledge for the chemical being evaluated, as well as the needs of various regulatory authorities', indicating that DIT and/or DNT cohorts should be considered on a case by case basis as part of this TG, also in an effort to maximize information and reduce the number of used animals.

With regard to DIT, early-life environmental insults, by affecting the developing immune system, may significantly impact health of the exposed offspring and, possibly, future generations. Therefore, DIT may play an important role in the onset of non-communicable diseases, as commented by Dietert and co-authors (Dietert 2009; Dietert et al. 2010). DIT has been traditionally assessed in vivo, and most literature reviews on this endpoint have focused on animal research and specific categories of risk factors (e.g., heavy metals). Systematic reviews (and meta-analyses) of human epidemiological studies [such as (Dietert 2014)] are needed to support DIT risk identification. Furthermore, experience gathered across chemical and pharmaceutical industries globally suggests that triggered-based testing approaches together with standard toxicity studies may help evaluate DIT potential (Boverhof et al. 2014). Possible triggers may be: (i) signs of immunotoxicity observed in standard toxicity studies, (ii) a test compound with potential to affect immune functions, (iii) the intended patient population resulting already immunocompromised, (iv) a test compound that is structurally similar to other known immunotoxicants, (v) a drug retained at high concentrations in immune system cells, and (vi) signs of potential immunotoxicity that have been observed in clinical findings (Boverhof et al. 2014).

\section{Endocrine disruptors (EDs)}

Since the late 1990s, endocrine disruptors (EDs) are in the focus of the OECD, with the creation of the advisory group on endocrine disruptors testing and assessment (EDTA AG) and the development of several test methods investigating endocrine activity or ED-related effects. Also the European Commission adopted a Community Strategy for endocrine disruptors in 1999 (EC 1999), which was recently revised (EC 2018c).

According to the 2002 IPCS/WHO broadly accepted definition of EDs, an ED is 'an exogenous substance or mixture that alters function( $(s)$ of the endocrine system and consequently causes adverse health effects in an intact organism, or its progeny, or (sub)populations' (IPSC and WHO 2002).

The main challenge for ED testing is to design test methods complex enough to cover the entire signalling network and the relevant modes of action (MoA). Additionally, current in vivo and non-animal approaches do not easily allow the prediction of effects later in life as a consequence of early life or developmental exposure. Human epidemiological data may be available eventually once health problems have been associated with chemical exposures; however, causal links to specific chemical exposures may be difficult to identify, especially considering the delay in appearance of the health effects in relation to the timing of exposure.

Under REACH (2020g), at the moment, specific information on ED properties is not required; however, reproductive toxicity [e.g., EOGRTS (OECD 20181)] and organ-related toxicity studies might provide relevant information on $\mathrm{ED}$ properties. Additional specific studies during chemical evaluation can be required where concerns about possible EDrelated effects are raised. The cosmetics regulation also does not require specific information on ED properties, although a list of potential EDs has been made and the dossiers of these compounds, compiled by the cosmetics industry, are currently under consideration by the SCCS.

The OECD Conceptual Framework for the testing and assessment of EDs has focused on interference with the action and production of sex steroid hormones (oestrogen and androgens) as well as interference with the thyroid 
hormone system. Some in vitro OECD TGs to study such endocrine-related effects [i.e., (anti)oestrogenicity, (anti) androgenicity and steroidogenesis] are available, such as: OECD TG 455 (OECD 2016h), OECD TG 493 (OECD 2015g), OECD TG 458 (OECD 2020c), and OECD TG 456 (OECD 2011). Beyond methods specifically designed for the detection of these endocrine MoAs in vivo (OECD TGs 440 and 441), and reproduction/developmental studies (OECD TGs 414, 421/422, 426, 416, and 443), repeated dose toxicity studies (here summarised under "Repeated dose toxicity" section and Table 2) can also be used to assess parameters sensitive to endocrine MoAs. Existing gaps and weaknesses in current test methods for the evaluation of EDs have been discussed in 2017 during a European expert workshop, the results of which were published in a 2018 report (EC 2018b).

One of the activities undertaken by EURL ECVAM in this context is the revision of OECD TG 458 (OECD 2020c) to include several Androgen Receptor Transactivation Assays (ARTAs). This TG is based on validated ARTAs: AR-EcoScreen (OECD 2015a), AR-CALUX (EC 2017b), or the ARTA based on 22Rv1/MMTV cell line (Sun et al. 2016).

Several screening approaches have been proposed in recent years to improve the regulatory assessment of chemicals for possible ED effects. A screening approach to prioritise substances for regulatory evaluation has been developed by ECHA, and it includes screening for potential ED properties (ECHA 2019). It is envisioned that rather than individual assays, a combination of assays (test battery) or a tiered screening strategy, including a WoE evaluation, may be more useful, as commented also by Paul Friedman and co-authors with regard to a possible screening approach to identify thyroperoxidase inhibitors (Paul Friedman et al. 2016).

Importantly, to date there are no specific OECD TGs addressing thyroid toxicity in vitro. With regard to thyroid disruptors and strategies to better assess chemicals for their thyroid signalling disrupting effects, the OECD has generated a Detailed Review Paper (OECD 2006), and has compiled a detailed scoping document summarising available in vitro and ex vivo methods suitable for the identification of thyroid disruptors (OECD 2014b). In March 2017, DG Environment and ANSES (the French Agency for Food, Environmental and Occupational Health and Safety) held a Thyroid Disruptor workshop (EC 2017e) with the goal to address and discuss interpretations of experimental data (i.e., laboratory studies, wildlife field data and human epidemiological data) in relation to the identification of thyroid disruptors, and to identify ways forward in addressing potential gaps in test methods.

In 2017, EURL ECVAM launched a call to the members of the European Union Network of Laboratories for the Validation of Alternative Methods (EU-NETVAL) (https:// ec.europa.eu/jrc/en/eurl/ecvam/alternative-methods-toxic ity-testing/eu-netval) for participation in a validation study with a selected number of in vitro methods suitable to measure thyroid disruptors (EC 2017c). The final aim of this validation activity is to attain a set of methods suitable to cover the known targets of thyroid disruption and that could in the future be included in OECD TGs.

Moreover, at the end of 2017, a call for tender was launched by DG Environment for the development of a study protocol for thyroid disruptor testing in the mammalian system, with the aim to improve the identification of thyroid disruptors, by either enhancing already existing OECD TGs and/or developing a new one. In particular, the endpoints that were considered during the feasibility study were: (i) heterotopias, (ii) hormone measurements, and (iii) cortical gene expression. These endpoints may be potentially added to EOGRTS (OECD TG 443) (EC 2019c).

Additionally, the H2020-funded cluster EURION, with its eight projects running for 5 years from beginning of 2019 , focuses on new and improved methods, as well as screening and testing strategies for thyroid hormone disruption, endocrine-related metabolic diseases, female reproductive effects and DNT (https://eurion-cluster.eu/). The outcome of the projects will contribute to international activities on EDs at OECD level (EC 2020c).

The provisions for identifying EDs in different pieces of EU legislation, including REACH and the Cosmetic Products Regulation, are reviewed in a recently completed Fitness Check, led by the JRC (EC 2020d). The Fitness Check identified the need to update the information requirements, particularly under REACH, to improve the possibilities to identify those substances with endocrine disrupting properties. Such an update is currently in progress, which will consider the inclusion of both in vitro and in vivo mechanistic OECD TGs that can identify endocrine activity, as well as some in vivo TGs that have been enhanced to include endocrine-related endpoints. The Fitness Check also indicated that available OECD TGs are not sufficient to cover all the different ways in which the endocrine system may be disrupted. The ongoing research projects and validation activities described above will serve to provide new methods, with broader coverage, that can be adopted as OECD TGs and serve to build testing strategies for EDs, including the use of new approach methodologies (NAMs). 


\section{Other challenges in the current regulatory landscape and recent initiatives to tackle them}

\section{Mixture risk assessment (MRA)}

In recent years, EU regulators have been facing several other challenges, such as (and not limited to) the definition of harmonized strategies to assess risks from combined exposure to multiple chemicals (i.e., mixture risk assessment, MRA). Exposure to multiple chemicals at the same time occurs in our daily life, and while the basic science and derived knowledge of mixture toxicology have progressed over the last years, it is still a matter of debate how to implement MRA in the current regulatory framework (Bopp et al. 2018b, 2019).

General principles for mixture toxicity assessment are outlined in Fig. 1.1 of the CLP Guidance (ECHA 2017c), which show the criteria to be followed for each hazard class independently, with the exception of substances classified as carcinogenic, mutagenic, or toxic for reproduction (CMR substances), or when evaluating biodegradation and bioaccumulation properties. Also in Appendix 1 of CLP Regulation (EC 2017d), paragraphs 1.1.3. report 'Bridging principles for the classification of mixtures where test data are not available for the complete mixture'. Similar principles for mixture toxicity assessment are reported in the GHS (UNGHS 2019), which provides harmonized criteria for mixtures classification according to their health, environmental and physical hazards in the sections specific to the different endpoints. It should be considered that CLP or any other European Regulation does not require mixture toxicity testing.

At present, each chemical is subject to an individual risk assessment, whereas MRA is usually not (appropriately) considered (Tralau et al. 2015). Moreover, EU chemical regulations operate (almost exclusively) in regulatory remits (i.e., on a chemical-by-chemical basis), but this approach may not be appropriate in cases when two or more chemicals elicit the same toxic effect (Evans et al. 2016). Methodologies to characterize combined effects and the possibility to assign substances to one or several common assessment groups have been discussed in two EFSA Scientific opinions related to active substances in plant protection products (EFSA 2013a, b) and a general Guidance document (EFSA 2019). In particular, the EFSA Panel on Plant Protection Products and their Residues (PPR) suggested that MRA could be assessed starting from the concept of dose addition for both, chemicals acting through similar MoA and those acting through dissimilar MoA, when leading to the same adverse effect (EFSA 2013b).

The most recent consolidated version of CLP (EC 2017d) provides classification criteria for mixtures for the different endpoints considered above, providing bridging principles when data are not available for the complete mixture, or are available only for some components of the mixture. Also dose addition-based concepts are suggested. Under REACH, combinations of chemicals are only addressed for multi-constituent substances (MCS) and substances of unknown or variable composition, complex reaction products or of biological origin (UVCBs). However, four phthalates were restricted under REACH on the basis of a risk assessment considering their combined exposure and results from monitoring studies with a limit value referring to their combined un-intentional exposures (ECHA 2017a).

With regards to cosmetic ingredients, usually they are assessed individually and in combinations in the composition of the final products. When data are available from industry or from European Agencies, other products than cosmetics, including the same ingredients, are also considered in the assessment.

To facilitate MRA, it has been shown how mechanistic information derived using twenty-first century methods in combination with AOPs and networks of AOPs (see also "Strategic and conceptual frameworks to integrate alternative methods in current EU regulatory context" section) could support and enable assessing mixtures in componentbased and whole-mixture approaches (Bopp et al. 2018b, 2019).

\section{Implementing the 3Rs in current regulatory testing paradigm}

Strategies to integrate up-to-date in vitro and in silico methods and models in existing or new regulatory testing strategies have been discussed at the European and international level, and efforts to develop harmonized recommendations to ensure worldwide acceptance of alternative methods and strategies have been globally undertaken (e.g., with the ICATM initiative). At the European level, Directive 2010/63/EU (EU 2010) on the protection of animals used for scientific purposes includes a number of duties (Article 48 and Annex VII) to foster the 3Rs. Additionally, several pieces of EU Regulations, such as REACH (EC 2020g) and the Cosmetic Products Regulation (EC 2020e) and their amendments have contributed to the implementation of the 3Rs, by referring to, and encouraging the use of, alternatives to animal testing. More recently, the Community Strategies on combined exposures (Bopp et al. 2015, 2018a; Kienzler et al. 2016) and on EDs (Bopp et al. 2017; Munn et al. 2016) support the use of non-animal methods for safety assessment.

Since the publication of such regulations and GDs, much progress has been made with the promotion, implementation and validation of alternatives to animal 
Fig. 1 Bar graph summarising the numbers of available OECD Test Guidelines (TGs) addressing the assessment of the human health-related endpoints here described, comparing in vivo TGs (black bars) and in vitro/in chemico TGs (white bars)

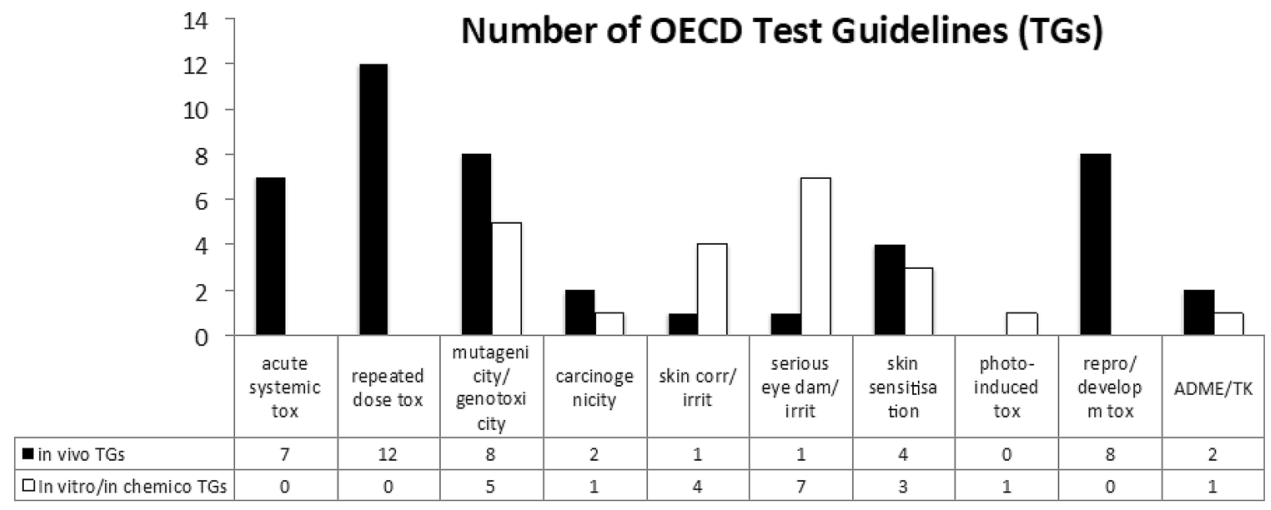

testing. This is reflected by the fact that, for some specific endpoints, chemicals are often tested using non-animal approaches, for example in the case of skin corrosion and irritation and serious eye damage/irritation (with globally 11 in vitro OECD TGs), skin sensitisation (with 3 available in vitro/in chemico OECD TGs), and mutagenicity/genotoxicity (with 5 available in vitro OECD TGs) (Fig. 1, white bars). Notwithstanding, chemical evaluation still heavily relies on the use of animals (mainly rodents), in particular for acute systemic toxicity, repeated dose toxicity and reproductive and developmental toxicity (Fig. 1, black bars).

With regards to the number of animal used for scientific purposes, Directive 2010/63/EU has put in place a more comprehensive reporting framework for Member States, and in February 2020, more precise estimates of animal use in Europe during the years 2015 to 2017 have been made available. In this report, mice, fish, rats and birds, together represent over $92 \%$ of the total numbers of animals used for scientific purposes, with most uses being in basic research (45\%), followed by translational/ applied research (23\%) and regulatory use (23\%) (EC 2020a). Notably, the report also expresses concern with the uses of animals in areas where alternative methods have already reached regulatory acceptance (such as in the areas of skin irritation/corrosion, serious eye damage/eye irritation, and pyrogenicity testing) (EC 2020a).

Remarkably, as commented in the ECHA's fourth report on the use of alternative methods to animal testing under REACH (ECHA 2020), read-across is becoming the most commonly used adaptation, which has led to a reduction of experimental studies; additionally, the use of in vitro and in chemico non-animal test methods has tripled for skin corrosion/irritation, quadrupled for serious eye damage/eye irritation and increased by more than 20 -fold for skin sensitisation.

\section{Strategic and conceptual frameworks to integrate alternative methods in current EU regulatory context}

The development of alternative test methods based on the use of human cells and tissue cultures (from monolayer cell (co)cultures, to organotypic three-dimensional (3D) cell models, microfluidics organ-on-chip systems, 3D- and 4D-bioprinting, etc.), multiple highthroughput 'omics' technologies, and computational analytical methods (e.g., IVIVE, PBK, and pharmacodynamics), may in the future contribute to reduce the number of animals used in both biomedical research and regulatory toxicology.

While the application of such individual approaches may not be suitable to adequately mimic complex physiological and toxicological endpoints, the integration of in vitro (and in silico) methods may mimic certain aspects of biological complexity, to enable the prediction of certain human health effects ideally better than animal studies. It is considered that the use of human-derived cells and tissues, coupled with microphysiological system approaches (Marx et al. 2016), will increase the predictive capacity of toxicological effects of chemicals or new drugs to humans (Archibald et al. 2018), while enabling mechanistic understanding of how chemicals and drugs produce their effects (Dehne et al. 2017; Tralau et al. 2012; Wobus and Loser 2011).

As described in "Implementing the 3Rs in current regulatory testing paradigm" section, some of the current OECD TGs are based on the use of alternative approaches (Fig. 1), supporting the 3Rs. Also, waiving principles are in place to reduce the number of animals, and after the marketing ban of cosmetics tested on animals in 2013, testing of cosmetic ingredients is no longer possible under the Cosmetic Products Regulation, and this has triggered 
the development of new approaches based on non-animal methods and models (SCCS 2018). Nevertheless, regulators generally have traditionally adopted a cautious approach when discussing the possibility to phase out traditional animal approaches in favour of alternative methods, which has been justified on the basis of the need to treat human safety as paramount (Tralau et al. 2012). One of the major arguments in favour of this precautionary attitude is the fact that alternative methods may be integrated in current regulatory testing approaches only upon their international acceptance and validation. Nevertheless, it is worth noticing that most in vivo methods have never been formally validated (Tralau et al. 2015).

In vitro methods may also allow elucidating how inter-species differences can have an impact on chemical response, as shown for instance in Baumann et al. study, where differences in chemical effects on neurodevelopmental key events were described comparing human and rat neurospheres (Baumann et al. 2016). Several studies have highlighted species-specific differences, e.g., in the pace of development (Rayon et al. 2020), in liver cytochrome P450 and transport protein (Hammer et al. 2021), in the metabolic capacity and clearance of liver microsomes (Ma et al. 2017), in the expression of GABA-A receptor in T lymphocytes (Mendu et al. 2012), in the expression of nociceptive markers and ion channels between human and mouse iPSCderived nociceptors (Schoepf et al. 2020). Altogether, this underlines the importance to test chemical effects on human toxicological endpoints using human-relevant test systems. It should also be considered that the inherent limitations of in vitro testing should be accepted in the same way as in vivo testing limitations are currently accepted (Tralau et al. 2012). An approach to systematically describe the uncertainties and complexity of the standard animal testing and assessment approach on the example of carcinogenicity has been explored by Paparella et al. (Paparella et al. 2017).

In the last decade, several strategies have been undertaken by different organizations and institutions, such as EURL ECVAM (EC 2017b, 2018a), to promote the development and the dissemination of alternative methods and approaches, encouraging the assessment of chemicals without relying on animal testing, covering different regulatory areas and their related needs. In this context, the AOP conceptual framework is currently considered as a relevant instrument in toxicology, as it allows portraying existing knowledge concerning the association between a molecular initiating event (MIE) and an adverse outcome (AO) in a chemical-agnostic way at different levels of biological complexity that are relevant to risk assessment (i.e., any chemical perturbing the MIE with sufficient potency and duration is likely to trigger that AOP) (Leist et al. 2017). The process of developing AOPs is nowadays well defined and efforts have been made to support broad and international participation through training and outreach (Edwards et al. 2016). This 'mode of action' framework further enables the development of IATA, which represents a science-based pragmatic approach suitable for the characterisation of chemical hazard. Such approaches rely on an integrated analysis of existing information, together with the generation of new information using testing strategies (OECD 2020a). IATA, by following an iterative method, are meant to answer a defined question in a specific regulatory context, accounting for the uncertainty associated with the decision context, and can include results of assays at various levels of biological complexity, such as in silico, (Q)SAR, read-across, in chemico, in vitro, ex vivo, in vivo, omics technologies, and AOPs (Edwards et al. 2016).

AOP-driven IATA could facilitate regulatory decision regarding potential hazards, and the risk and/or the need for further targeted testing. To define the safe and unsafe concentrations for risk assessment, potency information would be needed, and some IATA (e.g., for skin sensitisation) might be able to account for these aspects.

IATA for skin irritation/corrosion, serious eye damage/ eye irritation and skin sensitisation are discussed in the OECD GDs 203 (OECD 2014a), 263 (OECD 2017b), and 256 (OECD 2016c), respectively. Such IATA include three parts: (i) retrieving and gathering of existing information, (ii) WoE analysis on all collected information, and, if no conclusion can be drawn, (iii) generation of new testing data. In particular, given the complexity of the skin sensitisation pathway, a one-to-one replacement of animal testing with a single non-animal method has not been attained so far, and instead a combination of different assays to capture different KEs of this AOP (Covalent Protein binding leading to Skin Sensitisation) (Landesmann and Dumont 2012; OECD 2012) represents a more reliable approach. For this specific endpoint (skin sensitisation), various in vitro assays have been formally validated and adopted at the regulatory level (Table 2): the direct peptide reactivity assay (DPRA) and Amino acid Derivative Reactivity Assay (ADRA) [TG 442C (OECD 2020b)], the KeratinoSens ${ }^{\mathrm{TM}}$ and LuSens assays [TG 442D (OECD 2018j)] and assays addressing the activation of dendritic cells (h-CLAT, U-SENSTM and IL-8 Luc test methods) included in TG 442E (OECD 2018k). Along this line, a number of Defined Approaches (DAs) integrating information from multiple non-animal methods (e.g., in silico, in chemico, in vitro) and other relevant information (e.g., physico-chemical properties) have been developed for the purpose of skin sensitisation hazard assessment and/or potency categorisation. The OECD GD 255 (OECD 2016d) provides principles and templates for reporting DAs to testing and assessment that can be used as either stand-alone or one of the components within IATA. 
In the context of IATA, the OECD GD 275 (OECD 2017a) describes four IATA case studies as examples of predictions that are fit for regulatory use, relying specifically on alternative methods and taking into account exposure considerations and kinetics.

The OECD Project 4.116 added to the OECD Test Guidelines workplan in 2017 and led by EURL ECVAM, ICCVAM and Health Canada, aims to develop a Guideline on DAs for Skin Sensitisation. Following a special meeting of the Working Group of National Coordinators of the Test Guideline programme (WNT) in December 2017, an Expert Group on DAs for Skin Sensitisation (DASS), was convened in early 2018. Through face-to-face meetings, teleconferences and written commenting, the Expert Group provided input on a framework for evaluating DAs, and has applied the evaluation criteria to a first set of relatively simple, rulebased DAs based on OECD adopted in chemico and in vitro test methods. These DAs are under consideration for inclusion in a draft Guideline that aims to substitute the animal tests.

Moreover, several competitive research projects, such as SEURAT-1 (www.seurat-1.eu), EU-ToxRisk (www.eu-toxri sk.eu), and EuroMix (www.euromixproject.eu) have been launched in recent years in Europe, with the main goal to promote the use of alternative methods and progress towards an animal-free toxicological assessment. In particular, EUToxRisk, a continuation of the prior FP7 research initiative SEURAT-1, integrates advancements in cell biology, 'omics' technologies, systems biology and computational modelling to increase mechanistic understanding of cause-consequence relationships of chemical adverse effects. EuroMix specifically aims at developing an experimental tiered strategy for the risk assessment of mixtures of chemicals derived from multiple sources, taking into account prioritisation criteria for chemicals based on their exposure and hazard characteristics, and evaluating the role of MoA in grouping chemicals into cumulative assessment groups.

Along the same line, EDC-MixRisk (http://edcmixrisk. ki.se/) integrates epidemiology and experimental biology to improve risk assessment of exposure to mixtures of EDs. Another project, HBM4EU-The European Human Biomonitoring Initiative (www.hbm4eu.eu) aims at coordinating and advancing human biomonitoring in Europe, providing better evidence of the correlations between chemical exposure and possible health effects, and supporting policy-making.

Finally, following an OECD mandate, EURL ECVAM has drafted a guidance document on Good In Vitro Method Practices (GIVIMP) (OECD 2018a), taking into account good scientific, technical and quality practices aimed at ensuring that in vitro method development and implementation for regulatory use become more efficient and effective. Altogether, these projects and initiatives may help bridge current gaps in regulatory testing, and facilitate a paradigm shift towards a mechanistically driven hazard identification, characterization and risk assessment.

\section{Discussion}

Understanding current regulatory requirements for the assessment of chemical and cosmetic ingredient effects on human health is essential to identify possible knowledge gaps, and evaluate how alternative methods could be better integrated in current regulatory landscape. Along this line, EU regulations call for the use of alternative non-animal methods, and over the last decade, an increasing number of alternative approaches has been developed and formally adopted. These methods have increased mechanistic understanding of toxicological effects, contributing to better hazard identification and risk assessment. However, several issues still need to be faced, such as the need to (i) better characterize toxicity pathways, (ii) develop assays suitable to bridge currently uncovered scientific gaps, (iii) increase our understanding of the links between in vitro readouts and the (adverse) outcomes in target species, (iv) better define applicability domains for alternative methods, and (v) foster the broad and harmonized implementation of currently available alternative methods. These were recognized as major challenges by different stakeholders participating in a EPAA (European Partnership for Alternative Approaches to Animal Testing) meeting organized in 2016 (Dal Negro et al. 2018).

Notably, regulatory requirements for the safety assessment of industrial chemicals and cosmetic products differ, as described in this document. To tackle complex and systemic toxicity effects, integration of available information on relevant endpoints, encompassing data derived from traditional and alternative toxicology test systems, together with most recent data streams and epidemiology data sources, should be considered, as it has been recently discussed in the context of carcinogenicity testing (Corvi et al. 2017; Madia et al. 2019). Sharing of data and international cooperation among governmental bodies, as the one fostered by the ICATM initiative, are essential to improve the capacity to solve complex problems, as commented in the "OECD Regulatory Policy Outlook 2018” (OECD 2018b).

With the advancement of new technologies and models in bioscience developed by academia and industry, dialogue and knowledge sharing should span beyond the regulatory testing arena. Along this line, a recent EURL ECVAM initiative, called BEAMS (BridgE Across Methods in bioSciences) (EC 2018a), aimed at supporting greater connectivity between biosciences, and understanding how knowledge sharing and meaningful cross-disciplinarity can play a role and what form it should take. 
Efficacy and predictive capacity of currently available in vivo TGs are intensively debated and generally questioned in relation to their applicability to humans (species extrapolation) as well as their sensitivity to pick up effects. It is generally perceived that a one-to-one replacement of an in vivo TG or method with an in vitro (non-animal) one is not a suitable way forward, and that biological complexity may better be mimicked by a combination of in vitro and in silico tests, following the IATA framework. Such integrated testing should in principle be able to predict human health effects better than animal studies (Archibald et al. 2018; Hartung 2009; Marx et al. 2016), helping to unravel the molecular and cellular mechanisms underlying the effects of chemicals, cosmetic products (and drugs) on human health (Dehne et al. 2017; Tralau et al. 2012; Wobus and Loser 2011). Beside the technical debate, 'relying on data from alternatives also needs a change in mind-set, from a box ticking exercise into a fit for purpose hypothesis-driven strategy for generating relevant data', as emphasized in the Cosmetics Europe annual conference 2018 report (Europe 2018). A check-list approach based on in vivo TGs does not efficiently meet legislative mandates that require increased numbers of chemical assessments without a parallel increase in the use of animals and resources. These new approaches are necessary to close the gap between the number of chemicals in use and the number assessed to date.

Moreover, the recently published EU Chemicals Strategy for Sustainability, aiming at a toxic-free environment under the European Green Deal (EC 2020b) calls for innovation in chemicals safety testing to reduce dependency on animal testing. The strategy highlights the importance to improve the quality, efficiency and speed of chemical hazard and risk assessments using advanced tools, methods and models, and data analysis capacities. It is becoming more and more evident that traditional animal testing approaches simply do not match the current needs anymore. The strategy can only be effective if the paradigm-shift in toxicity testing, advocated 15 years ago, is finally becoming fully functional.

Notably, current information requirements are essentially based on apical adverse effect endpoints observed in animal tests. The current approach to replacing such tests attempts to directly relate and match mechanistic data obtained with new technologies and models with apical effects; on the other hand, a better approach might be to revise the information requirements on the basis of new ways of describing toxicity hazard to better exploit these new data streams. Indeed, it is at the moment very difficult, if not impossible, to classify a chemical on the basis of mechanistic data within the framework of current GHS and CLP criteria, which are currently based on animal studies. Work has recently started at UN level to revise the GHS criteria with a view to include in vitro, in silico and in chemico methods, as well as grouping and read across, as a basis for hazard assessment, with the ultimate goal to adapt the criteria to non-animal data.

With the increasing interconnectedness of economies and global communication, the discussion about the use of nonanimal methods has clearly expanded beyond the scientific and regulatory remits, and concerns regarding the use of animals for scientific and regulatory purposes have been globally raised by the general public. A 2014 USA poll, aimed at exploring public attitudes toward the use of animals for scientific purposes, highlighted that about $47 \%$ of interviewed participants were in favour of the practice, while about $50 \%$ opposed it, with a trend towards a decreased support for animal research since 2009 (Center 2015; Sullivan 2016). Similar polls have been carried out to depict Europeans' view on this matter, with analogous results (Clemence and Leaman 2016; EC 2010).

It is noteworthy that a trend towards the 'democratization of science' has been observed, and it is therefore becoming progressively important to understand public attitudes toward current scientific practice, and engage the society on such issues (Ormandy and Schuppli 2014). The recent European Citizens' Initiative (ECI) Stop Vivisection (http:// www.stopvivisection.eu/), which demanded an abrogation of Directive 2010/63/EU on the protection of animals used for scientific purposes and a full replacement of animal tests with alternative methods (Menache 2016), should be proactively taken by regulators and the scientific community as an opportunity to develop new ways to engage the public on such issues, expanding the boundaries in the debate on the use of animals for scientific purposes. Again, dialogue with all stakeholders and knowledge sharing are pivotal to advance towards the goal of phasing out animal testing, as commented in the EC reply to ECI Stop Vivisection (EC 2015b). Recent EC initiatives are working towards this direction; in particular, EURL ECVAM had undertaken a review to map 3Rs knowledge, determine how knowledge is shared, and identify opportunities to improve on the current situation (Holley et al. 2016).

Importantly, the acceptance and use of alternative methods also require careful monitoring and appraisal by the Competent Authorities. In this regard, the European Coalition to End Animal Experiments (ECEAE), grouping about 20 animal protection organisations across the EU (https:// www.eceae.org/), carried out an independent analysis of the publicly available national reports on animals used for scientific purposes (EC 2019a) (Taylor and Rego 2016). This analysis highlighted four specific regulatory tests recorded in these statistical reports, i.e., (i) skin irritation (as typically using rabbits), (ii) eye irritation (as exclusively using rabbits), (iii) skin sensitisation (as typically using mice or Guinea pigs), and (iv) pyrogenicity tests (as exclusively using rabbits), although these tests have accepted 
alternatives to their use, recognised under the EU legislation. While in recent years an increasing trend in the use of alternative methods for skin sensitisation has been observed, in areas such as skin irritation/corrosion, serious eye damage/ eye irritation and pyrogenicity testing, concerns still exist with regards to animal uses, as highlighted in the most recent European statistics (EC 2020a).

Additionally, since the 2013 EU marketing ban of cosmetics tested on animals (EC 2013a), the European Parliament has further launched a resolution for a world-wide ban of animal testing for cosmetics (EP 2018), with the support of the EC. As commented by Cosmetics Europe (Europe 2018), the EU ban presents several caveats [e.g., in the case of cosmetics that are tested outside of the EU on animals and re-tested using alternative methods for the EU market, or considering that the testing and marketing bans do not apply to testing required for environmental endpoints or exposure of workers (ECHA 2014b)], which make the ban far less effective. Taking all these aspects into account, current acceptance and use of alternative (non-animal) methods and TGs should be a matter of transparent and open debate among all stakeholders.

Furthermore, the development of new methods (and subsequent validation/evaluation and uptake) mainly occurs as a consequence of increased funding and market opportunities. For example, the ban on animal testing for cosmetic ingredients and products triggered the development of new non-animal approaches within the cosmetics industry. Moreover, the pharmaceutical industry is also developing and using new in vitro methods and in silico technologies (e.g., machine learning and artificial intelligence), which have recently shown more promising than animal models to predict human responses (Freedman 2019; Yau et al. 2017).

ICATM will continue to explore the future outlook of NAMs in regulatory testing frameworks and identify opportunities and obstacles for their uptake in the respective ICATM jurisdictions in a world of growing awareness of the global interconnectedness of human and environmental health.

Acknowledgements The authors would like to thank Laura Rossi from ECHA and Vera Rogiers, member of the SCCS, for their constructive comments on the manuscript.

\section{Declarations}

Conflict of interest The authors have no conflict of interests to declare.

Open Access This article is licensed under a Creative Commons Attribution 4.0 International License, which permits use, sharing, adaptation, distribution and reproduction in any medium or format, as long as you give appropriate credit to the original author(s) and the source, provide a link to the Creative Commons licence, and indicate if changes were made. The images or other third party material in this article are included in the article's Creative Commons licence, unless indicated otherwise in a credit line to the material. If material is not included in the article's Creative Commons licence and your intended use is not permitted by statutory regulation or exceeds the permitted use, you will need to obtain permission directly from the copyright holder. To view a copy of this licence, visit http://creativecommons.org/licenses/by/4.0/.

\section{References}

Adler S, Basketter D, Creton S et al (2011) Alternative (non-animal) methods for cosmetics testing: current status and future prospects-2010. Arch Toxicol 85(5):367-485. https://doi.org/10. 1007/s00204-011-0693-2

Archibald K, Tsaioun K, Kenna JG, Pound P (2018) Better science for safer medicines: the human imperative. J R Soc Med. https://doi. org $/ 10.1177 / 0141076818812783$

Balls M, Hellsten E (2002) Statement on the scientific validity of the postimplantation rat whole-embryo culture assay-an in vitro test for embryotoxicity. Altern Lab Anim 30(3):271-273

Bal-Price A, Fritsche E (2018) Editorial: developmental neurotoxicity. Toxicol Appl Pharmacol 354:1-2. https://doi.org/10.1016/j. taap.2018.07.016

Bal-Price A, Pistollato F, Sachana M, Bopp SK, Munn S, Worth A (2018) Strategies to improve the regulatory assessment of developmental neurotoxicity (DNT) using in vitro methods. Toxicol Appl Pharmacol 354:7-18. https://doi.org/10.1016/j.taap.2018. 02.008

Baumann J, Gassmann K, Masjosthusmann S et al (2016) Comparative human and rat neurospheres reveal species differences in chemical effects on neurodevelopmental key events. Arch Toxicol 90(6):1415-1427. https://doi.org/10.1007/s00204-015-1568-8

Bessems J, Coecke S, Gouliarmou V, Whelan M, Worth A (2015) EURL ECVAM strategy for achieving 3Rs impact in the assessment of toxicokinetics and systemic toxicity. http://publications. jrc.ec.europa.eu/repository/bitstream/JRC96418/eurl\%20ecvam\% 20toxicokinetics\%20strategy.pdf. Accessed 9 Oct 2019

Bjorling-Poulsen M, Andersen HR, Grandjean P (2008) Potential developmental neurotoxicity of pesticides used in Europe. Environ Health 7:50. https://doi.org/10.1186/1476-069x-7-50

Bopp S, Berggren E, Kienzler A, Van der Linden S, Worth A (2015) Scientific methodologies for the assessment of combined effects of chemicals - a survey and literature review. JRC Technical Report, document number EUR 27471 EN, ISBN 978-92-7951925-3 (PDF). https://doi.org/10.2788/093511, http://publicatio ns.jrc.ec.europa.eu/repository/bitstream/JRC97522/jrc_tech_rep_ sci\%20meth\%20for\%20mix_final.pdf

Bopp S, Nepelska M, Halder M, Munn S (2017) Expert survey on identification of gaps in available test methods for evaluation of endocrine disruptors. Publications Office of the European Union. Document number EUR 28592 EN, ISBN 978-92-7968778-5. https://doi.org/10.2760/844100, https://publications.jrc. ec.europa.eu/repository/handle/JRC106244

Bopp S, Richarz A, Worth A, Berggren E, Whelan M (2018a) Something from nothing? Ensuring the safety of chemical mixtures. Publications Office of the European Union. Document number EUR 29258 EN, ISBN 978-92-79-86747-7. https://doi.org/10. 2760/618648, https://publications.jrc.ec.europa.eu/repository/ handle/JRC111886

Bopp SK, Barouki R, Brack W et al (2018b) Current EU research activities on combined exposure to multiple chemicals. Environ Int 120:544-562. https://doi.org/10.1016/j.envint.2018.07.037

Bopp SK, Kienzler A, Richarz AN et al (2019) Regulatory assessment and risk management of chemical mixtures: challenges and 
ways forward. Crit Rev Toxicol 49(2):174-189. https://doi.org/ 10.1080/10408444.2019.1579169

Boverhof DR, Ladics G, Luebke B et al (2014) Approaches and considerations for the assessment of immunotoxicity for environmental chemicals: a workshop summary. Regul Toxicol Pharmacol 68(1):96-107. https://doi.org/10.1016/j.yrtph.2013.11.012

Brendler-Schwaab S, Czich A, Epe B et al (2004) Photochemical genotoxicity: principles and test methods. Report of a GUM task force. Mutat Res 566(1):65-91

Buesen R, Oberholz U, Sauer UG, Landsiedel R (2018) Comment on "Alternative acute oral toxicity assessment under REACH based on sub-acute toxicity values." Altex 35(1):119-121. https://doi. org/10.14573/altex.1710111

Casati S, Aschberger K, Barroso J et al (2018) Standardisation of defined approaches for skin sensitisation testing to support regulatory use and international adoption: position of the International Cooperation on Alternative Test Methods. Arch Toxicol 92(2):611-617. https://doi.org/10.1007/s00204-017-2097-4

CDC (2018) Data \& Statistics on Autism Spectrum Disorder. https:// www.cdc.gov/ncbddd/autism/data.html. Accessed Feb 202019

Center PR (2015) Chapter 7: Opinion About the Use of Animals in Research. http://www.pewinternet.org/2015/07/01/chapter-7opinion-about-the-use-of-animals-in-research/. Accessed 27 Feb 2019

ChemSafetyPro (2018) What Is Point of Departure (POD) and How to Use It to Calculate Toxicological Reference Dose (RfD). https:// www.chemsafetypro.com/Topics/CRA/What_is_Point_of_Depar ture_(POD)_in_Toxicology_and_How_to_Use_It_to_Calculate_ Reference_Dose_RfD.html

Clemence M, Leaman J (2016) Public attitudes to animal research in 2016 Ipsos Mori Social Research Institute

Corvi R, Madia F, Guyton KZ et al (2017) Moving forward in carcinogenicity assessment: report of an EURL ECVAM/ESTIV workshop. Toxicol In Vitro 45(Pt 3):278-286. https://doi.org/ 10.1016/j.tiv.2017.09.010

Crofton KM, Mundy WR, Shafer TJ (2012) Developmental neurotoxicity testing: a path forward. Congenit Anom (Kyoto) 52(3):140146. https://doi.org/10.1111/j.1741-4520.2012.00377.x

Curren RD, Mun GC, Gibson DP, Aardema MJ (2006) Development of a method for assessing micronucleus induction in a 3D human skin model (EpiDerm). Mutat Res 607(2):192-204. https://doi. org/10.1016/j.mrgentox.2006.04.016

Dakeishi M, Murata K, Tamura A, Iwata T (2006) Relation between benchmark dose and no-observed-adverse-effect level in clinical research: effects of daily alcohol intake on blood pressure in Japanese salesmen. Risk Anal 26(1):115-123. https://doi.org/10. 1111/j.1539-6924.2006.00722.x

Dal Negro G, Eskes C, Belz S et al (2018) One science-driven approach for the regulatory implementation of alternative methods: a multi-sector perspective. Regul Toxicol Pharmacol 99:33-49. https://doi.org/10.1016/j.yrtph.2018.08.002

Daniel AB, Strickland J, Allen D et al (2018) International regulatory requirements for skin sensitization testing. Regul Toxicol Pharmacol 95:52-65. https://doi.org/10.1016/j.yrtph.2018.03.003

Dehne EM, Hasenberg T, Marx U (2017) The ascendance of microphysiological systems to solve the drug testing dilemma. Future Sci OA 3(2):FSO185. https://doi.org/10.4155/fsoa-2017-0002

Dietert RR (2009) Developmental immunotoxicology: focus on health risks. Chem Res Toxicol 22(1):17-23. https://doi.org/10.1021/ tx $800198 \mathrm{~m}$

Dietert RR (2014) Developmental immunotoxicity, perinatal programming, and noncommunicable diseases: focus on human studies. Adv Med 2014:867805. https://doi.org/10.1155/2014/867805

Dietert RR, DeWitt JC, Germolec DR, Zelikoff JT (2010) Breaking patterns of environmentally influenced disease for health risk reduction: immune perspectives. Environ Health Perspect 118(8):1091-1099. https://doi.org/10.1289/ehp.1001971

EC (1999) Community Strategy for Endocrine Disrupters a range of substances suspected of interfering with the hormone systems of humans and wildlife. vol COM (1999) 706 final, Brussels, 17.12.1999

EC (2003) SCCNFP/0690/03. Notes of Guidance for testing of cosmetic ingredients and their safety evaluation

EC (2009) Regulation (EC) No 1107/2009 of the European Parliament and of the Council of 21 October 2009 concerning the placing of plant protection products on the market and repealing Council Directives 79/117/EEC and 91/414/EEC

EC (2010) Science and Technology vol Special Eurobarometer 340

EC (2012) Regulation (EU) No 528/2012 of the European Parliament and of the Council of 22 May 2012 concerning the making available on the market and use of biocidal products Text with EEA relevance, Chapter 13 vol 049, pp 181-303

EC (2013a) COM/2013/135 Communication from the Commission to the European Parliament and the Council on the animal testing and marketing ban and on the state of play in relation to alternative methods in the field of cosmetics. https://eur-lex.europa.eu/ legal-content/en/TXT/?uri=CELEX:52013DC0135

EC (2013b) Commission Regulation (EU) No 283/2013 of 1 March 2013 setting out the data requirements for active substances, in accordance with Regulation (EC) No 1107/2009 of the European Parliament and of the Council concerning the placing of plant protection products on the market Text with EEA relevance

EC (2014) Commission Regulation (EU) No 260/2014 of 24 January 2014 amending, for the purpose of its adaptation to technical progress, Regulation (EC) No 440/2008 laying down test methods pursuant to Regulation (EC) No 1907/2006 of the European Parliament and of the Council on the Registration, Evaluation, Authorisation and Restriction of Chemicals (REACH) Text with EEA relevance. https://eur-lex.europa.eu/legal-content/ $\mathrm{EN} / \mathrm{TXT} /$ ?uri=celex\%3A32014R0260. Accessed 15 Oct 2020

EC (2015a) Commission Regulation (EU) 2015/282 https://eur-lex. europa.eu/legal-content/EN/TXT/?uri=uriserv:OJ.L_.2015.050. 01.0001.01.ENG

EC (2015b) Commission replies to "Stop Vivisection" European Citizens' Initiative. http://europa.eu/rapid/press-release_IP-15-5094_ en.htm. Accessed 27 Feb 2019

EC (2016) Commission Regulation (EU) 2016/863 of 31 May 2016 amending Annexes VII and VIII to Regulation (EC) No 1907/2006 of the European Parliament and of the Council on the Registration, Evaluation, Authorisation and Restriction of Chemicals (REACH) as regards skin corrosion/irritation, serious eye damage/eye irritation and acute toxicity. https://eur-lex. europa.eu/legal-content/EN/TXT/?uri=CELEX:32016R0863

EC (2017a) Commission Regulation (EU) 2017/706 of 19 April 2017 amending Annex VII to Regulation (EC) No 1907/2006 of the European Parliament and of the Council on the Registration, Evaluation, Authorisation and Restriction of Chemicals $(\mathrm{REACH})$ as regards skin sensitisation and repealing Commission Regulation (EU) 2016/1688. https://eur-lex.europa.eu/ legal-content/en/TXT/?uri=CELEX:32017R0706. Accessed 1 Oct 2020

EC (2017b) EURL ECVAM status report on the development, validation and regulatory acceptance of alternative methods and approaches

EC (2017c) European drive to validate in vitro methods for the detection of thyroid disruptors. https://ec.europa.eu/jrc/en/scienceupdate/vitro-methods-detection-thyroid-disruptors. Accessed 27 Feb 2019

EC (2017d) Regulation (EC) No 1272/2008 concerning the Classification Labelling and Packaging (CLP). https://eur-lex.europa.eu/ 
legal-content/EN/TXT/PDF/?uri=CELEX:02008R1272-20170 101\&from=EN. Accessed $27 \mathrm{Feb} 2019$

EC (2017e) Supporting the organisation of a workshop on thyroid disruption. https://doi.org/10.2779/921523

EC (2018a) EURL ECVAM Status Report on the Development, Validation and Regulatory Acceptance of Alternative Methods and Approaches

EC (2018b) Setting priorities for further development and validation of test methods and testing approaches for evaluating endocrine disruptors. https://doi.org/10.2779/21828

EC (2018c) Towards a comprehensive European Union framework on endocrine disruptors. vol COM(2018) 734 final, Brussels, 7.11.2018

EC (2019a) Animals used for scientific purposes. EU Member States national statistical reports (2014 and onward). http://ec.europa. eu/environment/chemicals/lab_animals/member_states_stats_ reports_en.htm. Accessed 1 Mar 2019

EC (2019b) Council Regulation (EC) No 440/2008 of 30 May 2008 laying down test methods pursuant to Regulation (EC) No 1907/2006 on the Registration, Evaluation, Authorisation and Restriction of Chemicals (REACH). https://eur-lex.europa.eu/ legal-content/EN/TXT/?uri=CELEX:02008R0440-20191016. Accessed 15 Oct 2020

EC (2019c) Development of a study protocol for thyroid disruptor testing in the mammalian system

EC (2020a) 2019 report on the statistics on the use of animals for scientific purposes in the Member States of the European Union in 2015-2017. vol COM(2020) 16 final, Brussels, 5.2.2020

EC (2020b) Communication from the Commission to the European Parliament, the Council, the European Economic and Social Committee and The Committee of the Regions-Chemicals Strategy for Sustainability-Towards a Toxic-Free Environment. vol COM/2020/667 final

EC (2020c) EURL ECVAM Status Report on the Development, Validation and Regulatory Acceptance of Alternative Methods and Approaches (2019)

EC (2020d) Fitness Check on endocrine disruptors. Commission Staff Working document. SWD(2020) 251 final. https://ec.europa.eu/ environment/pdf/chemicals/2020/10/SWD_on_Endocrines_disru ptors.pdf. Accessed 23 Oct 2020

EC (2020e) Regulation (EC) No 1223/2009 of the European Parliament and the Council of 30 November 2009 on cosmetic products. https://eur-lex.europa.eu/legal-content/EN/TXT/?uri=CELEX: 02009R1223-20200501. Accessed 15 Oct 2020

EC (2020f) Regulation (EC) No 1272/2008 concerning the Classification Labelling and Packaging (CLP). https://eur-lex.europa.eu/ legal-content/EN/TXT/?uri=CELEX:02008R1272-20200501. Accessed 15 Oct 2020

EC (2020g) Regulation (EC) No 1907/2006 concerning the Registration, Evaluation, Authorisation and Restriction of Chemicals (REACH). https://eur-lex.europa.eu/legal-content/EN/TXT/? uri=CELEX:02006R1907-20200428. Accessed 15 Oct 2020

ECHA (2012) Guidance on information requirements and chemical safety assessment Chapter R.8: Characterisation of dose [concentration]-response for human health. http://echa.europa. eu/documents/10162/13632/information_requirements_r8_en. pdf. Accessed 27 Feb 2019

ECHA (2014a) Factsheet. Interface between REACH and Cosmetics regulations. ECHA-14-FS-04-EN. https://echa.europa.eu/docum ents/10162/13628/reach_cosmetics_factsheet_en.pdf. Accessed 27 Feb 2019

ECHA (2014b) Factsheet. Interface between REACH and Cosmetics regulations. ECHA-14-FS-04-EN. https://echa.europa.eu/docum ents/10162/13628/reach_cosmetics_factsheet_en.pdf. Accessed 9 Oct 2019
ECHA (2017a) Committee for Risk Assessment (RAC) and Committee for Socio-economic Analysis (SEAC) Opinion on an Annex XV dossier proposing restrictions on FOUR PHTHALATES (DEHP, BBP, DBP, DIBP). vol March 2017

ECHA (2017b) ECHA Guidance on Information Requirements and Chemical Safety Assessment, Chapter R.7a: Endpoint specific guidance Version 6.0. https://echa.europa.eu/documents/10162/ 13632/information_requirements_r7a_en.pdf

ECHA (2017c) Guidance on the Application of the CLP Criteria. Version 5.0

ECHA (2019) Endocrine disruptor assessment. In. https://echa.europa. eu/it/ed-assessment. Accessed 27 Feb 2019

ECHA (2020) The use of alternatives to testing on animals for the REACH Regulation

ECI Stop Vivisection. http://www.stopvivisection.eu/. Accessed 1 April 2021

Edwards SW, Tan YM, Villeneuve DL, Meek ME, McQueen CA (2016) Adverse outcome pathways-organizing toxicological information to improve decision making. J Pharmacol Exp Ther 356(1):170-181. https://doi.org/10.1124/jpet.115.228239

EFSA (2013a) Scientific Opinion on the identification of pesticides to be included in cumulative assessment groups on the basis of their toxicological profile. EFSA J 11:3293

EFSA (2013b) Scientific Opinion on the relevance of dissimilar mode of action and its appropriate application for cumulative risk assessment of pesticides residues in food. EFSA J 11:3472

EFSA (2019) Guidance on harmonised methodologies for human health, animal health and ecological risk assessment of combined exposure to multiple chemicals. EFSA J 17(3):5634

EFSA (2020) Technical Report on the Outcome of the pesticides peer review meeting on general recurring issues in mammalian toxicology. vol EFSA-Q-2020-00170, p 26

Elespuru R, Pfuhler S, Aardema MJ et al (2018) Genotoxicity assessment of nanomaterials: recommendations on best practices, assays, and methods. Toxicol Sci 164(2):391-416. https://doi. org/10.1093/toxsci/kfy 100

EP (2018) A global ban on animal testing for cosmetics. 2017/2922(RSP). http://www.europarl.europa.eu/sides/getDoc. do?pubRef $=-/ /$ EP//TEXT+TA+P8-TA-2018-0202+0+DOC+ $\mathrm{XML}+\mathrm{V} 0 / / \mathrm{EN} \&$ language $=\mathrm{EN}$. Accessed 1 Mar 2019

EU (2010) Directive 2010/63/EU on the protection of animals used for scientific purposes. https://eur-lex.europa.eu/LexUr iServ/LexUriServ.do?uri=OJ:L:2010:276:0033:0079:en:PDF. Accessed 26 Feb 2019

EU-NETVAL (European Union Network of Laboratories for the Validation of Alternative Methods). https://ec.europa.eu/jrc/ en/eurl/ecvam/alternative-methods-toxicity-testing/eu-netval. Accessed 1 April 2021

Europe C Cosmetic Europe Annual Conference 2018 Report. In: Cosmetic Europe Annual Conference 2018, Brussels, 2018

Evans RM, Martin OV, Faust M, Kortenkamp A (2016) Should the scope of human mixture risk assessment span legislative/regulatory silos for chemicals? Sci Total Environ 543(Pt A):757764. https://doi.org/10.1016/j.scitotenv.2015.10.162

Freedman DH (2019) Hunting for new drugs with AI. Nature 576(7787):S49-S53. https://doi.org/10.1038/ d41586-019-03846-0

Gilmour N, Kern PS, Alepee N et al (2020) Development of a next generation risk assessment framework for the evaluation of skin sensitisation of cosmetic ingredients. Regul Toxicol Pharmacol 116:104721. https://doi.org/10.1016/j.yrtph.2020. 104721

Gissi A, Louekari K, Hoffstadt L, Bornatowicz N, Aparicio AM (2017) Alternative acute oral toxicity assessment under REACH based on sub-acute toxicity values. Altex 34(3):353-361. https://doi. org/10.14573/altex.1609121 
Gissi A, Louekari K, Hoffstadt L, Bornatowicz N, Aparicio AM (2018) Reply to Comment on "Alternative acute oral toxicity assessment under REACH based on sub-acute toxicity values." Altex 35(1):121-122. https://doi.org/10.14573/altex.1712011

Graepel R, Asturiol D, Prieto P, Worth AP (2016) Exploring waiving opportunities for mammalian acute systemic toxicity tests. Altern Lab Anim 44(3):271-279

Grandjean P, Landrigan PJ (2006) Developmental neurotoxicity of industrial chemicals. Lancet 368(9553):2167-2178. https://doi. org/10.1016/s0140-6736(06)69665-7

Hammer H, Schmidt F, Marx-Stoelting P, Potz O, Braeuning A (2021) Cross-species analysis of hepatic cytochrome P450 and transport protein expression. Arch Toxicol 95(1):117-133. https://doi.org/ 10.1007/s00204-020-02939-4

Hartung T (2009) Toxicology for the twenty-first century. Nature 460(7252):208-212. https://doi.org/10.1038/460208a

Holley T, Bowe G, Campia I, et al (2016) Accelerating progress in the Replacement, Reduction and Refinement of animal testing through better knowledge sharing. vol EUR $28234 \mathrm{EN}$

ICATM International Cooperation on Alternative Test Methods (ICATM). https://ec.europa.eu/jrc/en/eurl/ecvam/alternativemethods-toxicity-testing/advisory-bodies/icatm. Accessed 1 April 2021

IPSC, WHO (2002) Global assessment of the state-of-the-science of endocrine disruptors. vol WHO/PCS/EDC/02.2

Jacobs MN, Colacci A, Louekari K et al (2016) International regulatory needs for development of an IATA for non-genotoxic carcinogenic chemical substances. Altex 33(4):359-392. https://doi.org/ 10.14573/altex.1601201

Jacobs MN, Colacci A, Corvi R et al (2020) Chemical carcinogen safety testing: OECD expert group international consensus on the development of an integrated approach for the testing and assessment of chemical non-genotoxic carcinogens. Arch Toxicol 94(8):2899-2923. https://doi.org/10.1007/s00204-020-02784-5

Kadereit S, Zimmer B, van Thriel C, Hengstler JG, Leist M (2012) Compound selection for in vitro modeling of developmental neurotoxicity. Front Biosci (Landmark Ed) 17:2442-2460

Kienzler A, Bopp SK, van der Linden S, Berggren E, Worth A (2016) Regulatory assessment of chemical mixtures: requirements, current approaches and future perspectives. Regul Toxicol Pharmacol 80:321-334. https://doi.org/10.1016/j.yrtph.2016.05.020

Landesmann B, Dumont C (2012) AOP 40: Covalent Protein binding leading to Skin Sensitisation. https://aopwiki.org/aops/40

Leist M, Ghallab A, Graepel R et al (2017) Adverse outcome pathways: opportunities, limitations and open questions. Arch Toxicol 91(11):3477-3505. https://doi.org/10.1007/s00204-017-2045-3

Ma HY, Yang JD, Hou J et al (2017) Comparative metabolism of DDAO benzoate in liver microsomes from various species. Toxicol In Vitro 44:280-286. https://doi.org/10.1016/j.tiv.2017. 06.020

Madia F, Phrakonkham P, Corvi R (2014) Current and emerging in vitro methods for genotoxicity and carcinogenicity. In Vitro Toxicol Syst. https://doi.org/10.1007/978-1-4939-0521-8_14

Madia F, Worth A, Corvi R (2016) Analysis of carcinogenicity testing for regulatory purposes in the European Union Publications Office of the European Union. vol JRC100609

Madia F, Worth A, Whelan M, Corvi R (2019) Carcinogenicity assessment: addressing the challenges of cancer and chemicals in the environment. Environ Int 128:417-429. https://doi.org/10.1016/j. envint.2019.04.067

Marx U, Andersson TB, Bahinski A et al (2016) Biology-inspired microphysiological system approaches to solve the prediction dilemma of substance testing. Altex 33(3):272-321. https://doi. org/10.14573/altex.1603161

Menache A (2016) The European Citizens' Stop Vivisection Initiative and the revision of Directive. Altern Lab Anim 44(4):383-390
Mendu SK, Bhandage A, Jin Z, Birnir B (2012) Different subtypes of GABA-A receptors are expressed in human, mouse and rat $\mathrm{T}$ lymphocytes. PLoS ONE 7(8):e42959. https://doi.org/10.1371/ journal.pone.0042959

Mun GC, Aardema MJ, Hu T et al (2009) Further development of the EpiDerm 3D reconstructed human skin micronucleus (RSMN) assay. Mutat Res 673(2):92-99. https://doi.org/10.1016/j.mrgen tox.2008.12.004

Munn S, Worth A, Lostia A et al (2016) Screening methodology to identify potential endocrine disruptors according to different options in the context of an impact assessment. Document number EUR 27955, ISBN 978-92-79-58907-2. https://doi.org/10. 2788/288320, https://publications.jrc.ec.europa.eu/repository/ handle/JRC101950

NRC (2007) Toxicity testing in the 21st century: a vision and a strategy. https://doi.org/10.17226/11970

OECD (1981a) Test No. 410: Repeated Dose Dermal Toxicity: 21/28day Study. https://www.oecd-ilibrary.org/environment/test-no410-repeated-dose-dermal-toxicity-21-28-day-study_97892 64070745-en

OECD (1981b) Test No. 411: Subchronic Dermal Toxicity: 90-day Study. https://www.oecd-ilibrary.org/environment/test-no-411subchronic-dermal-toxicity-90-day-study_9789264070769-en

OECD (1986) Test No. 485: Genetic toxicology, Mouse Heritable Translocation Assay. https://www.oecd-ilibrary.org/environment/ test-no-485-genetic-toxicology-mouse-heritable-translocationassay_9789264071506-en

OECD (1992) Test No. 406: Skin Sensitisation. https://www.oecd-ilibr ary.org/environment/test-no-406-skin-sensitisation_9789264070 660 -en

OECD (1995) Test No. 419: Delayed Neurotoxicity of Organophosphorus Substances: 28-day Repeated Dose Study. https://www. oecd-ilibrary.org/environment/test-no-419-delayed-neurotoxic ity-of-organophosphorus-substances-28-day-repeated-dosestudy_9789264070929-en

OECD (1997a) Test No. 424: Neurotoxicity Study in Rodents. https:// www.oecd-ilibrary.org/environment/test-no-424-neurotoxicitystudy-in-rodents_9789264071025-en

OECD (1997b) Test No. 471: Bacterial Reverse Mutation Test. https:// www.oecd-ilibrary.org/environment/test-no-471-bacterial-rever se-mutation-test 9789264071247-en

OECD (1997c) Test No. 486: Unscheduled DNA Synthesis (UDS) Test with Mammalian Liver Cells in vivo. https://www.oecd-ilibrary. org/environment/test-no-486-unscheduled-dna-synthesis-udstest-with-mammalian-liver-cells-in-vivo_9789264071520-en

OECD (1998) Test No. 409: Repeated Dose 90-Day Oral Toxicity Study in Non-Rodents. https://www.oecd-ilibrary.org/envir onment/test-no-409-repeated-dose-90-day-oral-toxicity-studyin-non-rodents_9789264070721-en

OECD (2001) Test No. 416: Two-Generation Reproduction Toxicity. https://www.oecd-ilibrary.org/environment/test-no-416-twogeneration-reproduction-toxicity_9789264070868-en

OECD (2002a) Test No. 420: Acute Oral Toxicity - Fixed Dose Procedure. https://www.oecd-ilibrary.org/environment/test-no-420acute-oral-toxicity-fixed-dose-procedure_9789264070943-en

OECD (2002b) Test No. 423: Acute Oral toxicity - Acute Toxic Class Method. https://www.oecd-ilibrary.org/environment/test-no-423acute-oral-toxicity-acute-toxic-class-method_9789264071001-en

OECD (2004a) Test No. 427: Skin Absorption: In Vivo Method. https:// www.oecd-ilibrary.org/environment/test-no-427-skin-absorptionin-vivo-method_9789264071063-en

OECD (2004b) Test No. 428: Skin Absorption: In Vitro Method. https://www.oecd-ilibrary.org/environment/test-no-428-skinabsorption-in-vitro-method_9789264071087-en

OECD (2004c) Test No. 432: In Vitro 3T3 NRU Phototoxicity Test. https://www.oecd-ilibrary.org/environment/ 
test-no-432-in-vitro-3t3-nru-phototoxicity-test_9789264071 162 -en

OECD (2006) Detailed Review Paper on Thyroid Hormone Disruption Assays. No. 57., vol ENV/JM/MONO(2006)24

OECD (2007a) Test No. 426: Developmental Neurotoxicity Study. https://www.oecd-ilibrary.org/environment/test-no-426-devel opmental-neurotoxicity-study_9789264067394-en

OECD (2007b) Test No. 440: Uterotrophic Bioassay in Rodents. https://www.oecd-ilibrary.org/environment/test-no-440-utero trophic-bioassay-in-rodents_9789264067417-en

OECD (2008a) Test No. 407: Repeated Dose 28-day Oral Toxicity Study in Rodents. https://www.oecd-ilibrary.org/environment/ test-no-407-repeated-dose-28-day-oral-toxicity-study-in-roden ts_9789264070684-en. Accessed 27 Feb 2019

OECD (2008b) Test No. 425: Acute Oral Toxicity: Up-and-Down Procedure. https://www.oecd-ilibrary.org/environment/test-no-425acute-oral-toxicity-up-and-down-procedure_9789264071049-en

OECD (2009a) Test No. 403: Acute Inhalation Toxicity. https://www. oecd-ilibrary.org/environment/test-no-403-acute-inhalation-toxic ity_9789264070608-en

OECD (2009b) Test No. 436: Acute Inhalation Toxicity-Acute Toxic Class Method. https://www.oecd-ilibrary.org/environment/testno-436-acute-inhalation-toxicity-acute-toxic-class-method 9789264076037-en

OECD (2009c) Test No. 441: Hershberger Bioassay in Rats. https:// www.oecd-ilibrary.org/environment/test-no-441-hershbergerbioassay-in-rats_9789264076334-en

OECD (2010a) Test No. 417: Toxicokinetics. https://www.oecd-ilibr ary.org/environment/test-no-417-toxicokinetics_9789264070 882-en

OECD (2010b) Test No. 429: Skin Sensitisation. https://www.oecdilibrary.org/environment/test-no-429-skin-sensitisation_97892 64071100-en

OECD (2010c) Test No. 442A: Skin Sensitization. https://www.oecdilibrary.org/environment/test-no-442a-skin-sensitization_97892 64090972-en

OECD (2011) Test No. 456: H295R Steroidogenesis Assay. https:// www.oecd-ilibrary.org/environment/test-no-456-h295r-stero idogenesis-assay_9789264122642-en

OECD (2012) Series on Testing and Assessment No. 168. The Adverse Outcome Pathway for Skin Sensitisation Initiated by Covalent Binding to Proteins. Part 1: Scientific Evidence

OECD (2013) Test No. 488: Transgenic Rodent Somatic and Germ Cell Gene Mutation Assays. https://www.oecd-ilibrary.org/envir onment/test-no-488-transgenic-rodent-somatic-and-germ-cellgene-mutation-assays_9789264203907-en

OECD (2014a) New Guidance Document on an integrated approach on testing and assessment (IATA) for skin corrosion and irritation. No. 203

OECD (2014b) New Scoping Document on In Vitro and Ex Vivo Assays for the Identification of Modulators Of Thyroid Hormone Signalling. No. 207

OECD (2015a) 2nd Validation Study For Androgen Receptor (AR) Mediated Stably Transfected Transcriptional Activation (ARSTTA) Assay to Detect Androgenic and Anti-androgenic Activities: AR EcoScreenTM

OECD (2015b) Guidance Document on the in vitro Syrian Hamster Embryo (SHE) cell transformation assay. No. 214. vol ENV/ JM/MONO(2015) 18

OECD (2015c) Test No. 404: Acute Dermal Irritation/Corrosion. https://www.oecd-ilibrary.org/environment/test-no-404-acutedermal-irritation-corrosion 9789264242678-en

OECD (2015d) Test No. 430: In Vitro Skin Corrosion: Transcutaneous Electrical Resistance Test Method (TER). https://www.oecd-ilibr ary.org/environment/test-no-430-in-vitro-skin-corrosion-trans cutaneous-electrical-resistance-test-method-ter_9789264242 739 -en

OECD (2015e) Test No. 435: In Vitro Membrane Barrier Test Method for Skin Corrosion. https://www.oecd-ilibrary.org/environment/ test-no-435-in-vitro-membrane-barrier-test-method-for-skincorrosion_9789264242791-en

OECD (2015f) Test No. 439: In Vitro Skin Irritation: Reconstructed Human Epidermis Test Method. https://www.oecd-ilibrary.org/ environment/test-no-439-in-vitro-skin-irritation-reconstructedhuman-epidermis-test-method_9789264242845-en

OECD (2015g) Test No. 493: Performance-Based Test Guideline for Human Recombinant Estrogen Receptor (hrER) In Vitro Assays to Detect Chemicals with ER Binding Affinity. https://www. oecd-ilibrary.org/environment/test-no-493-performance-basedtest-guideline-for-human-recombinant-estrogen-receptor-hrer-invitro-assays-to-detect-chemicals-with-er-binding-affinity_97892 64242623-en

OECD (2016a) Guidance Document on Considerations for Waiving or Bridging of Mammalian Acute Toxicity Tests. No. 237

OECD (2016b) Guidance Document on the in vitro Bhas 42 cell transformation assay. No. 231

OECD (2016c) Guidance Document on the reporting of defined approaches and individual information sources to be used within integrated approaches to testing and assessment (IATA) for Skin Sensitisation. No. 256

OECD (2016d) Guidance Document on the reporting of defined approaches to be used within integrated approaches to testing and assessment. No. 255

OECD (2016e) Test No. 421: Reproduction/Developmental Toxicity Screening Test. https://www.oecd-ilibrary.org/environment/ test-no-421-reproduction-developmental-toxicity-screening-test_ 9789264264380-en

OECD (2016f) Test No. 422: Combined Repeated Dose Toxicity Study with the Reproduction/Developmental Toxicity Screening Test. https://www.oecd-ilibrary.org/environment/test-no-422-combi ned-repeated-dose-toxicity-study-with-the-reproduction-devel opmental-toxicity-screening-test_9789264264403-en. Accessed 27 Feb 2019

OECD (2016g) Test No. 431: In vitro skin corrosion: reconstructed human epidermis (RHE) test method. https://www.oecd-ilibrary. org/environment/test-no-431-in-vitro-skin-corrosion-reconstruc ted-human-epidermis-rhe-test-method_9789264264618-en

OECD (2016h) Test No. 455: Performance-Based Test Guideline for Stably Transfected Transactivation In Vitro Assays to Detect Estrogen Receptor Agonists and Antagonists. https://www. oecd-ilibrary.org/environment/test-no-455-performance-basedtest-guideline-for-stably-transfected-transactivation-in-vitroassays-to-detect-estrogen-receptor-agonists-and-antagonists 9789264265295-en

OECD (2016i) Test No. 473: In Vitro Mammalian Chromosomal Aberration Test. https://www.oecd-ilibrary.org/environment/test-no473-in-vitro-mammalian-chromosomal-aberration-test_97892 64264649-en

OECD (2016j) Test No. 474: Mammalian Erythrocyte Micronucleus Test. https://www.oecd-ilibrary.org/environment/test-no-474mammalian-erythrocyte-micronucleus-test_9789264264762-en

OECD (2016k) Test No. 475: Mammalian Bone Marrow Chromosomal Aberration Test. https://www.oecd-ilibrary.org/environment/testno-475-mammalian-bone-marrow-chromosomal-aberration-test_ 9789264264786-en

OECD (20161) Test No. 476: In Vitro Mammalian Cell Gene Mutation Tests using the Hprt and xprt genes. https://www.oecd-ilibr ary.org/environment/test-no-476-in-vitro-mammalian-cell-genemutation-tests-using-the-hprt-and-xprt-genes_9789264264 809-en 
OECD (2016m) Test No. 478: Rodent Dominant Lethal Test. https:// www.oecd-ilibrary.org/environment/test-no-478-rodent-domin ant-lethal-test_9789264264823-en

OECD (2016n) Test No. 483: Mammalian Spermatogonial Chromosomal Aberration Test. https://www.oecd-ilibrary.org/envir onment/test-no-483-mammalian-spermatogonial-chromosomalaberration-test_9789264264847-en

OECD (2016o) Test No. 487: In Vitro Mammalian Cell Micronucleus Test. https://www.oecd-ilibrary.org/environment/test-no-487-invitro-mammalian-cell-micronucleus-test_9789264264861-en

OECD (2016p) Test No. 489: In Vivo Mammalian Alkaline Comet Assay. https://www.oecd-ilibrary.org/environment/test-no-489in-vivo-mammalian-alkaline-comet-assay_9789264264885-en

OECD (2016q) Test No. 490: In Vitro Mammalian Cell Gene Mutation Tests Using the Thymidine Kinase Gene. https://www.oecd-ilibr ary.org/environment/test-no-490-in-vitro-mammalian-cell-genemutation-tests-using-the-thymidine-kinase-gene_9789264264 908-en

OECD (2017a) Chemical safety assessment workflow based on exposure considerations and non-animal methods Series on Testing \& Assessment No 275. vol ENV/JM/MONO(2017)27

OECD (2017b) Guidance Document on an Integrated Approach on Testing and Assessment (IATA) for Serious Eye Damage and Eye Irritation. No. 263

OECD (2017c) Test No. 402: Acute Dermal Toxicity. https://www. oecd-ilibrary.org/environment/test-no-402-acute-dermal-toxic ity_9789264070585-en

OECD (2017d) Test No. 405: Acute Eye Irritation/Corrosion. https:// www.oecd-ilibrary.org/environment/test-no-405-acute-eye-irrit ation-corrosion_9789264185333-en

OECD (2017e) Test No. 437: Bovine Corneal Opacity and Permeability Test Method for Identifying i) Chemicals Inducing Serious Eye Damage and ii) Chemicals Not Requiring Classification for Eye Irritation or Serious Eye Damage. https://www. oecd-ilibrary.org/environment/test-no-437-bovine-cornealopacity-and-permeability-test-method-for-identifying-i-chemi cals-inducing-serious-eye-damage-and-ii-chemicals-not-requi ring-classification-for-eye-irritation-or-serious-eye-damage 9789264203846-en

OECD (2017f) Test No. 460: Fluorescein Leakage Test Method for Identifying Ocular Corrosives and Severe Irritants. https://www. oecd-ilibrary.org/environment/test-no-460-fluorescein-leakagetest-method-for-identifying-ocular-corrosives-and-severe-irrit ants_9789264185401-en

OECD (2018a) Guidance Document on Good In Vitro Method Practices (GIVIMP). No. 286

OECD (2018b) OECD Regulatory Policy Outlook 2018

OECD (2018c) Test No. 408: Repeated Dose 90-Day Oral Toxicity Study in Rodents. https://www.oecd-ilibrary.org/environment/ test-no-408-repeated-dose-90-day-oral-toxicity-study-in-roden ts_9789264070707-en

OECD (2018d) Test No. 412: Subacute Inhalation Toxicity: 28-Day Study. https://www.oecd-ilibrary.org/environment/test-no-412subacute-inhalation-toxicity-28-day-study_9789264070783-en

OECD (2018e) Test No. 413: Subchronic Inhalation Toxicity: 90-day Study. https://www.oecd-ilibrary.org/environment/test-no-413subchronic-inhalation-toxicity-90-day-study_9789264070806-en

OECD (2018f) Test No. 414: Prenatal Developmental Toxicity Study. https://www.oecd-ilibrary.org/environment/test-no-414-prenataldevelopment-toxicity-study_9789264070820-en

OECD (2018g) Test No. 433: Acute Inhalation Toxicity: Fixed Concentration Procedure. https://www.oecd-ilibrary.org/environment/ test-no-433-acute-inhalation-toxicity-fixed-concentration-proce dure_9789264284166-en

OECD (2018h) Test No. 438: Isolated Chicken Eye Test Method for Identifying i) Chemicals Inducing Serious Eye Damage and ii) Chemicals Not Requiring Classification for Eye Irritation or Serious Eye Damage. https://www.oecd-ilibrary.org/envir onment/test-no-438-isolated-chicken-eye-test-method-for-ident ifying-i-chemicals-inducing-serious-eye-damage-and-ii-chemi cals-not-requiring-classification-for-eye-irritation-or-seriouseye-damage_9789264203860-en

OECD (2018i) Test No. 442B: Skin Sensitization. https://www.oecdilibrary.org/environment/test-no-442b-skin-sensitization_97892 64090996-en

OECD (2018j) Test No. 442D: In Vitro Skin Sensitisation. https:// www.oecd-ilibrary.org/environment/test-no-442d-in-vitro-skinsensitisation_9789264229822-en

OECD (2018k) Test No. 442E: In Vitro Skin Sensitisation. https:// www.oecd-ilibrary.org/environment/test-no-442e-in-vitro-skinsensitisation 9789264264359-en

OECD (20181) Test No. 443: Extended One-Generation Reproductive Toxicity Study. https://www.oecd-ilibrary.org/environment/testno-443-extended-one-generation-reproductive-toxicity-study 9789264185371-en

OECD (2018m) Test No. 451: Carcinogenicity Studies. https://www. oecd-ilibrary.org/environment/test-no-451-carcinogenicity-studi es_9789264071186-en

OECD (2018n) Test No. 452: Chronic Toxicity Studies. https://www. oecd-ilibrary.org/environment/test-no-452-chronic-toxicity-studi es_9789264071209-en

OECD (20180) Test No. 453: Combined Chronic Toxicity/Carcinogenicity Studies. https://www.oecd-ilibrary.org/environment/ test-no-453-combined-chronic-toxicity-carcinogenicity-studi es_9789264071223-en

OECD (2018p) Test No. 491: Short Time Exposure In Vitro Test Method for Identifying i) Chemicals Inducing Serious Eye Damage and ii) Chemicals Not Requiring Classification for Eye Irritation or Serious Eye Damage. https://www.oecd-ilibrary.org/envir onment/test-no-491-short-time-exposure-in-vitro-test-methodfor-identifying-i-chemicals-inducing-serious-eye-damage-and-iichemicals-not-requiring-classification-for-eye-irritation-or-serio us-eye-damage_9789264242432-en

OECD (2018q) Test No. 492: Reconstructed human Cornea-like Epithelium (RhCE) test method for identifying chemicals not requiring classification and labelling for eye irritation or serious eye damage. https://www.oecd-ilibrary.org/environment/ test-no-492-reconstructed-human-cornea-like-epithelium-rhcetest-method-for-identifying-chemicals-not-requiring-classifica tion-and-labelling-for-eye-irritation-or-serious-eye-damage_ 9789264242548-en

OECD (2019a) Test No. 494: Vitrigel-Eye Irritancy Test Method for Identifying Chemicals Not Requiring Classification and Labelling for Eye Irritation or Serious Eye Damage. https://www. oecd-ilibrary.org/environment/tg-494-vitrigel-eye-irritancytest-method-for-identifying-chemicals-not-requiring-classifica tion-and-labelling-for-eye-irritation-or-serious-eye-damage 9f20068a-en. Accessed 25 Mar 2020

OECD (2019b) Test No. 496: In vitro Macromolecular Test Method for Identifying Chemicals Inducing Serious Eye Damage and Chemicals Not Requiring Classification for Eye Irritation or Serious Eye Damage. https://www.oecd-ilibrary.org/environment/test-no496-in-vitro-macromolecular-test-method-for-identifying-chemi cals-inducing-serious-eye-damage-and-chemicals-not-requiringclassification-for-eye-irritation-or-serious-eye-damage_970e5 cd9-en. Accessed 25 Mar 2020

OECD (2020a) Overview of Concepts and Available Guidance related to Integrated Approaches to Testing and Assessment (IATA) Series on Testing and Assesment No 329. http://www.oecd.org/ chemicalsafety/risk-assessment/concepts-and-available-guida nce-related-to-integrated-approaches-to-testing-and-assessment. pdf. Accessed 23 Oct 2020 
OECD (2020b) Test No. 442C: In Chemico Skin Sensitisation. https:// www.oecd-ilibrary.org/environment/test-no-442c-in-chemicoskin-sensitisation_9789264229709-en

OECD (2020c) Test No. 458: Stably Transfected Human Androgen Receptor Transcriptional Activation Assay for Detection of Androgenic Agonist and Antagonist Activity of Chemicals. https://www.oecd-ilibrary.org/environment/test-no-458-stablytransfected-human-androgen-receptor-transcriptional-activationassay-for-detection-of-androgenic-agonist-and-antagonist-activ ity-of-chemicals_9789264264366-en. Accessed 1 Oct 2020

Ormandy EH, Schuppli CA (2014) Public attitudes toward animal research: a review. Animals (Basel) 4(3):391-408. https://doi. org/10.3390/ani4030391

Paini A, Leonard JA, Joossens E et al (2019) Next generation physiologically based kinetic (NG-PBK) models in support of regulatory decision making. Comput Toxicol 9:61-72. https://doi.org/ 10.1016/j.comtox.2018.11.002

Paparella M, Colacci A, Jacobs MN (2017) Uncertainties of testing methods: What do we (want to) know about carcinogenicity? Altex 34(2):235-252. https://doi.org/10.14573/altex.1608281

Paul Friedman K, Watt ED, Hornung MW et al (2016) Tiered highthroughput screening approach to identify thyroperoxidase inhibitors within the toxcast phase I and II chemical libraries. Toxicol Sci 151(1):160-180. https://doi.org/10.1093/toxsci/kfw034

Pfuhler S, Fellows M, van Benthem J et al (2011) In vitro genotoxicity test approaches with better predictivity: summary of an IWGT workshop. Mutat Res 723(2):101-107. https://doi.org/10.1016/j. mrgentox.2011.03.013

Pfuhler S, Pirow R, Downs TR et al (2020) Validation of the 3D reconstructed human skin Comet assay, an animal-free alternative for following-up positive results from standard in vitro genotoxicity assays. Mutagenesis. https://doi.org/10.1093/mutage/geaa009

Rayon T, Stamataki D, Perez-Carrasco R et al (2020) Species-specific pace of development is associated with differences in protein stability. Science. https://doi.org/10.1126/science.aba7667

Reisinger K, Blatz V, Brinkmann J et al (2018) Validation of the 3D Skin Comet assay using full thickness skin models: transferability and reproducibility. Mutat Res Genet Toxicol Environ Mutagen 827:27-41. https://doi.org/10.1016/j.mrgentox.2018.01.003

Rovida C, Hartung T (2009) Re-evaluation of animal numbers and costs for in vivo tests to accomplish REACH legislation requirements for chemicals - a report by the transatlantic think tank for toxicology (t(4)). Altex 26(3):187-208

Sachana M (2019) An international effort to promote the regulatory use of PBK models based on non-animal data. Comput Toxicol 11(19):23-24

Sachana M, Bal-Price A, Crofton KM et al (2019) International regulatory and scientific effort for improved developmental neurotoxicity testing. Toxicol Sci 167(1):45-57. https://doi.org/10.1093/ toxsci/kfy 211

SCCS (2010) Basic criteria for the in vitro assessment of dermal absorption of cosmetic ingredients. Document number SCCS/1358/10, ISBN 978-92-79-12747-2. https://doi.org/10. 2772/25843, https://ec.europa.eu/health/scientific_committees/ consumer_safety/docs/sccs_s_002.pdf

SCCS (2018) SCCS/1602/18. SCCS Notes of Guidance for the Testing of Cosmetic Ingredients and their Safety Evaluation, 10th revision. https://ec.europa.eu/health/sites/health/files/scientific_ committees/consumer_safety/docs/sccs_o_224.pdf

Schoepf CL, Zeidler M, Spiecker L et al (2020) Selected ionotropic receptors and voltage-gated ion channels: more functional competence for human induced pluripotent stem cell (iPSC)-derived nociceptors. Brain Sci. https://doi.org/10.3390/brainsci10060344
Smirnova L, Hogberg HT, Leist M, Hartung T (2014) Developmental neurotoxicity-challenges in the 21 st century and in vitro opportunities. Altex 31(2):129-156. https://doi.org/10.14573/ altex.1403271

Spielmann H, Seiler A, Bremer S et al (2006) The practical application of three validated in vitro embryotoxicity tests. The report and recommendations of an ECVAM/ZEBET workshop (ECVAM workshop 57). Altern Lab Anim 34(5):527-538. https://doi.org/ 10.1177/026119290603400504

Sullivan K (2016) It takes a village: stakeholder participation is essential to transforming science. Altern Lab Anim 44(5):411-415

Sun S, Park EJ, Choi YH, Lee HS, Ahn BY, Dong MS (2016) Development and pre-validation of an in vitro transactivation assay for detection of (anti)androgenic potential compounds using 22Rv1/ MMTV cells. Reprod Toxicol 60:156-166. https://doi.org/10. 1016/j.reprotox.2016.02.006

Taylor K, Rego L (2016) EU statistics on animal experiments for 2014. Altex 33(4):465-468. https://doi.org/10.14573/altex.1609291

Tralau T, Riebeling C, Pirow R et al (2012) Wind of change challenges toxicological regulators. Environ Health Perspect 120(11):14891494. https://doi.org/10.1289/ehp.1104782

Tralau T, Oelgeschlager M, Gurtler R et al (2015) Regulatory toxicology in the twenty-first century: challenges, perspectives and possible solutions. Arch Toxicol 89(6):823-850. https://doi.org/ 10.1007/s00204-015-1510-0

Tsuji R, Crofton KM (2012) Developmental neurotoxicity guideline study: issues with methodology, evaluation and regulation. Congenit Anom (Kyoto) 52(3):122-128. https://doi.org/10.1111/j. 1741-4520.2012.00374.x

UN-GHS (2019) United Nations Globally Harmonised System of classification and labelling of chemicals (GHS), 8th revision

UN-TDG (2019) Recommendations of the Transport of Dangerous Goods, Model Regulations, 21st revision

van Thriel C, Westerink RH, Beste C, Bale AS, Lein PJ, Leist M (2012) Translating neurobehavioural endpoints of developmental neurotoxicity tests into in vitro assays and readouts. Neurotoxicology 33(4):911-924. https://doi.org/10.1016/j.neuro.2011.10.002

WHO (2006) Environmental Health Criteria 235. Dermal Absorption. http://www.inchem.org/documents/ehc/ehc/ehc235.pdf

Wobus AM, Loser P (2011) Present state and future perspectives of using pluripotent stem cells in toxicology research. Arch Toxicol 85(2):79-117. https://doi.org/10.1007/s00204-010-0641-6

Worth A, Barroso J, Bremer S et al (2014) Alternative methods for regulatory toxicology - a state-of-the-art review European Commission. JRC Science and Policy Report. Document number EUR 26797 EN, ISBN 978-92-79-39651-9 (PDF). https://doi. org/10.2788/11111, http://publications.jrc.ec.europa.eu/repos itory/bitstream/JRC91361/echa_jrc_sla_report_public_05-0914_withcover\%20ipo.pdf

Yau E, Petersson C, Dolgos H, Peters SA (2017) A comparative evaluation of models to predict human intestinal metabolism from nonclinical data. Biopharm Drug Dispos 38(3):163-186. https:// doi.org/10.1002/bdd.2068

Yoon M, Campbell JL, Andersen ME, Clewell HJ (2012) Quantitative in vitro to in vivo extrapolation of cell-based toxicity assay results. Crit Rev Toxicol 42(8):633-652. https://doi.org/10.3109/ 10408444.2012 .692115

Publisher's Note Springer Nature remains neutral with regard to jurisdictional claims in published maps and institutional affiliations. 